\title{
NBS
}

Eechnical Note

No. 308

\section{DATA REDUCTION FOR STABLE AURORAL RED ARCS OBSERVED AT RAPID CITY, SOUTH DAKOTA}

J. E. Cruz, Robert Davies, L. K. Droppleman, E. Marovich,

L. R. Megill, M. H. Rees, Linda Reisbeck, and F. E. Roach

U. S. DEPARTMENT OF COMMERCE NATIONAL BUREAU OF STANDARDS 


\section{THE NATIONAL BUREAU OF STANDARDS}

The National Bureau of Standards is a principal focal point in the Federal Government for assuring maximum application of the physical and engineering sciences to the advancement of technology in industry and commerce. Its responsibilities include development and maintenance of the national stand. ards of measurement, and the provisions of means for making measurements consistent with those standards; determination of physical constants and properties of materials; development of methods for testing materials, mechanisms, and structures, and making such tests as may be necessary, particularly for government agencies; cooperation in the establishment of standard practices for incorporation in codes and specifications; advisory service to government agencies on scientific and technical problems; invention and development of devices to serve special needs of the Government; assistance to industry, business, and consumers in the development and acceptance of commercial standards and simplified trade practice recommendations; administration of programs in cooperation with United States business groups and standards organizations for the development of international standards of practice; and maintenance of a clearinghouse for the collection and dissemination of scientific, technical, and engineering information. The scope of the Bureau's activities is suggested in the following listing of its four Institutes and their organizational units.

Institute for Basic Standards. Electricity. Metrology. Heat. Radiation Physics. Mechanics. Applied Mathematics. Atomic Physics. Physical Chemistry. Laboratory Astrophysics.* Radio Standards Laboratory: Radio Standards Physics; Radio Standards Engineering.** Office of Standard Reference Data.

Institute for Materials Research. Analytical Chemistry. Polymers. Metallurgy. Inorganic Materials. Reactor Radiations. Cryogenics.** Office of Standard Reference Materials.

Central Radio Propagation Laboratory.** Ionosphere Research and Propagation. Troposphere and Space Telecommunications. Radio Systems. Upper Atmosphere and Space Physics.

Institute for Applied Technology. Textiles and Apparel Technology Center. Building Research. Industrial Equipment. Information Technology. Performance Test Development. Instrumentation. Transport Systems. Office of Technical Services. Office of Weights and Measures. Office of Engineering Standards. Office of Industrial Services.

* NBS Group, Joint Institute for Laboratory Astrophysics at the University of Colorado.

** Located at Boulder, Colorado. 


\title{
NATIONAL BUREAU OF STANDARDS Eechnical Note 308 Issued May 3, 1965
}

\section{DATA REDUCTION FOR STABLE AURORAL RED ARCS OBSERVED AT RAPID CITY, SOUTH DAKOTA}

J. E. Cruz, Robert Davies, L. K. Droppleman, E. Marovich, L. R. Megill, M. H. Rees, Linda Reisbeck, and F. E. Roach National Bureau of Standards

Boulder, Colorado

\begin{abstract}
NBS Technical Notes are designed to supplement the Bureau's regular publications program. They provide a means for making available scientific data that are of transient or limited interest. Technical Notes may be listed or referred to in the open literature.
\end{abstract}





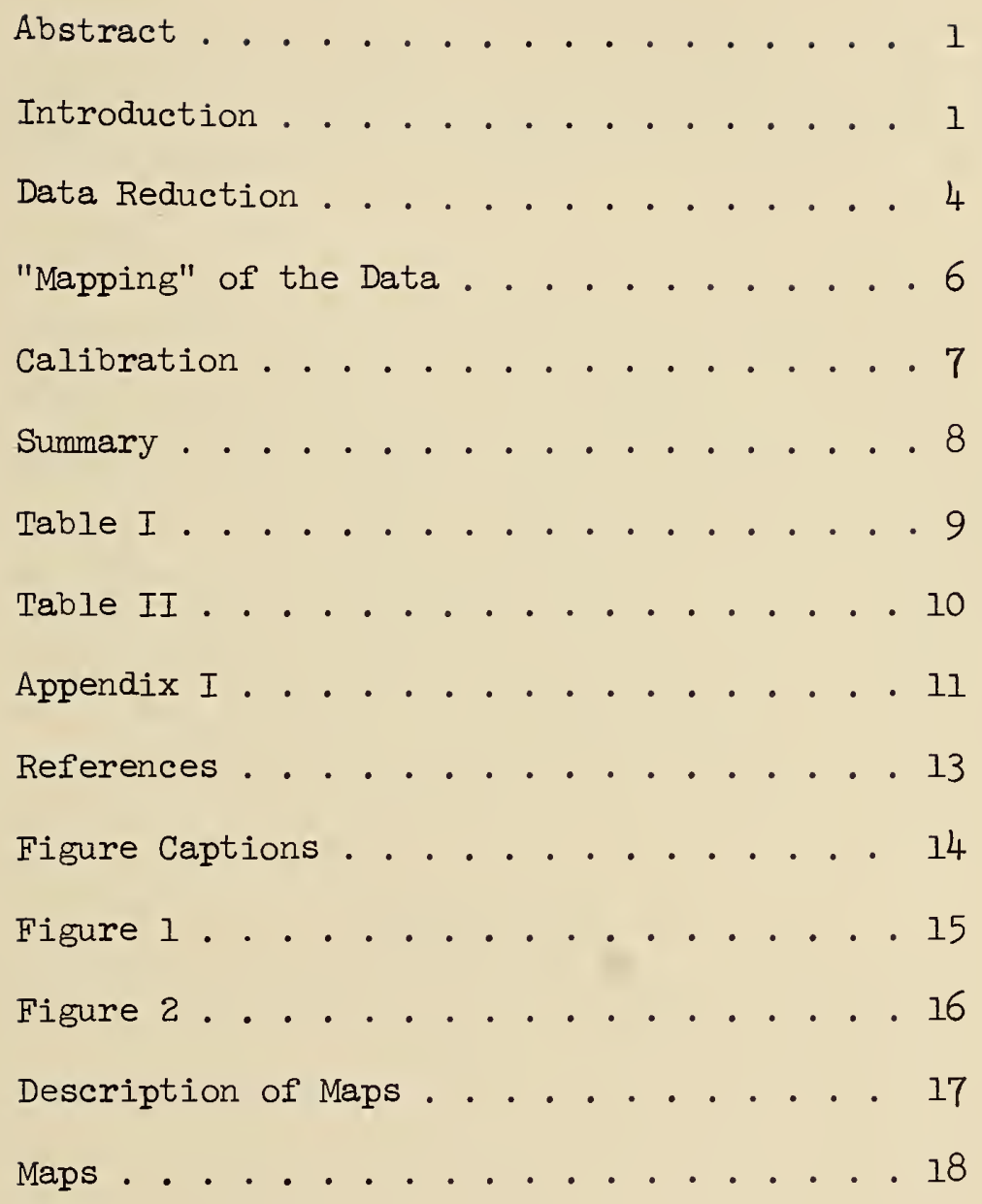



DATA REDUCTION FOR STABLE AURORAL RED ARCS OBSERVED AT RAPID CITY, SOUTH DAKOTA

J. E. Cruz, Robert Davies* , L. K. Droppleman, E. Marovich,

L. R. Megill, M. H. Rees ${ }^{+}$, Linda Reisbeck, and F. E. Roach

All sky photometric surveys in the $6300 \AA$ [OI] radiation obtained during the International Geophysical Year at Rapid City, South Dakota have been reduced. The analysis is described and the results for the night of September 16/17, 1958 are printed as isophote maps. These maps clearly show the presence of an arc and can be, therefore, a useful tool for further investigations of the stable auroral red arc.

\section{INTRODUCTION}

During the International Geophysical Year an airglow observing station was operated near Rapid City, South Dakota (Lat. 44³5'20", Long. $\left.103^{\circ} 18^{\prime} 50^{\prime \prime}\right)$. A number of observations were made of stable auroral red arcs (hereafter referred to as $S A R$-arcs ${ }^{\S}$ ) of the type first described by Barbier [1958]. Roach and Marovich [1960] have described the detailed morphology of a SAR-arc which occurred on October 22/23, 1958,

*University of Wisconsin, Department of Physics

${ }^{+}$University of Colorado, Department of Physics

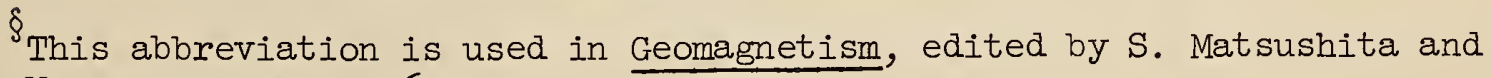
W. H. Campbell, 1965. 
and Marovich and Roach [1963] have analyzed the latitudinal distribution of 23 SAR-arcs observed at Rapid City.

A review of the phenomenon has been given by Roach and Roach [1963]; some reasonably well established properties of these arcs are:

1. They occur equatorward of the visual aurorae during a period of increased magnetic activity. From the reported observations, they appear to be oriented along parallels of geomagnetic latitude and occur in both hemispheres.

2. The extent ranges in height from $300-750 \mathrm{~km}$ and in latitude up to $4.5^{\circ}$.

3. There seems to be a tendency for the intensity of a SAR-arc to remain quite stable for many hours [Rees, 1961], in direct contrast to the rapid fluctuations characteristic of visible aurorae.

4. They have been observed at as high a geomagnetic latitude as $59^{\circ}$ and as low as $41^{\circ}$. There is some evidence that SAR-arcs occur simultaneously at least halfway around the globe.

5. Compared to normal nighttime conditions, the electron density within the arc is less and the height of the maximum density is greater.

6. The spectral composition consists predominantly of the 6300$6364 \AA$ doublet of [OI]. 
King and Roach [1961] explored the possibility that the excitation might be due to an enhancement of the rate of a recombination process which i presumed to be the principal excitation mechanism for the nighttime red airglow. The reactions concerned are:

$$
\mathrm{O}^{+}+\mathrm{N}_{2} \rightarrow \mathrm{NO}^{+}+\mathrm{N}
$$

and

$$
\mathrm{NO}^{+}+\mathrm{e} \rightarrow \mathrm{N}+O\left({ }^{\mathrm{I}} \mathrm{D}\right) \text {. }
$$

The first of these reactions is the slower at altitudes of interest here so that the intensity of emission is proportional to the product of $0^{+}$ and $\mathbb{N}_{2}$. It was found, however, that this would require an increase in $\mathrm{N}_{2}$ density by a factor of nearly 500 to explain the observed intensity. More recently several alternative possibilities have been discussed in the literature by Megill, Rees, and Droppleman [1963], Megill and Carleton [1964], Dalgarno [1964], and Cole [1965]. The hypotheses discussed in these papers have in common the requirement of excitation by electron collisions to excite the $O\left({ }^{l} D\right)$ but differ on the method by which they propose to get the energy into the electrons. They all have an implicit assumption that the arc is due to an interaction between the magnetosphere and the ionosphere.

The SAR-arc phenomenon is of interest then, not only in itself, but as a possible clue to mechanisms operative during magnetic storms. The data available in the Rapid City observations have not been thoroughly 
exploited. As a result the data for 23 nights on which the SAR-arc observed have been partially reduced and put on magnetic tape so that further investigations can be carried out with a minimum of effort. Table I gives a list of the nights for which data are available. - It is the purpose of this note to describe the preliminary operations which have been performed on these data in placing them on tape and to give in greater detail the behavior of a particularly good example of the arc on September 16/17, 1958. These further data involve the automatic "mapping" of the intensity in a manner which may prove useful to other investigators.

\section{DATA REDUCTION}

The original data are in the form of strip chart records. Records were obtained using a birefringent photometer as described by Megill [1959]. The data were obtained in five almucantar sweeps covering approximately the whole sky in five minutes for each of the three spectral lines observed. An entire sky survey was obtained every 15 mirutes. The field of view of the instrument was $4^{\circ}$.

The data for each degree in azimuth at zenith distances of $80^{\circ}$, $75^{\circ}, 70^{\circ}, 60^{\circ}, 40^{\circ}$, and the zenith were first placed on paper tape by means of a semi-automatic reader. During this operation care was taken to exclude doubtful data due to the presence of clouds or excessive sunlight. An approximate correction was made for scattering and extinction in the lower atmosphere using the equation

$$
I_{c}=R\left[I-\operatorname{Sc}(z) I_{\text {avg }}\right] e^{\tau m(z)}
$$


where $I$ is the record reading, $z$ is the zenith angle, $S c(z)$ is the correction for scattering, $\tau$ is the extinction coefficient and $m(z)$ is the air mass. (The air mass is unity in the zenith at sea level). The values of $\mathrm{Sc}(\mathrm{z}), \mathrm{e}^{\tau \mathrm{m}(\mathrm{z})}$ used are given in Table II. The constant $R$ is a calibration coefficient dependent on the instrument and was used to convert the intensities to Rayleighs. The average intensity is defined by:

$$
I_{\text {avg }}=\frac{1}{n} \Sigma\left[I-I_{0} \operatorname{Sc}(z)\right] e^{\tau m(z)} / V(z)
$$

where $n$ indicates the total number of readings in the survey, $I_{0}$ is the zenith intensity, and $\mathrm{V}$ is the van Rhijn function given by

$$
V(z)=\frac{1}{\sqrt{1-[E /(E+h)]^{2} \sin ^{2} z}}
$$

where $E$ is the radius of the earth and $h$ is the height of the emitting layer above the earth's surface (taken as $400 \mathrm{~km}$ ). What this process does, in effect, is to use the zenith intensity as a first approximation to the average intensity. A second approximation is then obtained using the deduced average. It should be noted that the correction applies strictly to a uniform intensity so that the application of Eq. (3) when an arc is in the sky represents an approximation even if $I_{\text {avg }}$ is accurately known. Using $I_{\text {avg }}$ in performing the scattering calculations gives results which are reliable to two digits within the region of the arc. There appears to be a tendency for this term to overcorrect in the region with no enhancement and the numbers are much less reliable. A more detailed discussion of the calibration technique is given in the section on calibration. 


\section{"MAPPING" OF THE DATA}

In order to portray the data an automatic mapping program has been prepared. Examples of the output of this program are shown in the maps included with this note. This program takes the data from the tape prepared as described above and makes a first order correction for the van Rhijn factor by assuming a constant height layer at $400 \mathrm{~km}$. In order to produce a "map" each recorded point is assigned a coordinate value in a polar coordinate system. A transformation from the polar coordinate values to the map matrix is made by assigning to each possible print location an intensity found by a linear interpolation between the two nearest intensities on the radium of the polar plot. All but the off scale values are normalized to 10.25 the highest printed value. As only one digit per location can be printed, values between 9.75 and 10.25 are printed as 0 ; values between 8.75 and 9.25 are printed as a 9, etc. The intermediate values as well as values below .75 are left blank. Where data were not obtained an $\mathrm{X}$ is printed and where the records were off scale a "+" is printed. The limit of resolution of this system varies from 1 part in 40 at the high intensities to 1 part in 4 at the lower intensities. This program allows the researcher to obtain a map giving a picture of the sky intensity without hand plotting. The night of September 16/17, 1958, has been plotted in this manner and included with this note. Additional data giving the time the survey was taken, an average intensity (AVG INT), and the zenith intensity (ZEN INT) in units of Rayleighs are printed at the side of the map. NORM, when multiplied by the digit of a particular spot on the map, gives the intensity in Rayleighs for that location (remembering zero = 10 ). 
A map relating the distance on the earth's surface to the corresponding zenith angle is given in Figure 1 . The height of the arc was assumed to be $400 \mathrm{~km}$ throughout the analysis. As one would expect, the height of the SAR-arc greatly affects the distances at the large zenith angles. Radial distances for various heights have been calculated as a function of the zenith angle and are shown in Figure 2.

\section{CAIIBRATION}

The absolute calibration in the $6300 \AA$ radiation rests, on the average calibration obtained for the $[O I](\lambda 5577$ ) radiation throughout the period of operation of the Rapid City photometer. Beginning with the calibration for $\lambda 5577$ a factor was applied which considered 1 ) the different photo-multiplier tube response, 2) the interference prefilter characteristics, and 3) the birefringent filter characteristics. The $\lambda 5577$ calibration in turn is based on (a) intercalibration with the Fritz Peak photometer by triangulation on the same patch of night sky, and (b) inter-calibration with the Fritz Peak instruments by means of an auxiliary portable photometer transported between the two stations on several occasions. The calibration of the Fritz Peak instruments, at the time, was based on star crossings. The precision (intermal consistency) of the data is within 10\%. The absolute calibration is probably not better than a factor of 2. For a discussion of accuracy in such photometric observations the reader is referred to Roach and Smith [1964] and Smith and Alexander [1963]. 


\section{SUMMARY}

Preliminary operations performed to make the I.G.Y. data on Stable Auroral Red Arcs available for quick usage are described. These data are available in the form described to researchers who wish to use them. In addition, if it should be desired, the program which will map the data can be made available. The data are on magnetic tape in binary format. The proper Fortran call and end of record instructions are given in Appendix I.

\footnotetext{
Two of the co-authors, Davies and Rees, were supported in this investigation by NSF Grant GP620.
} 
1957

$\underline{1958}$

Nov. $6 / 7$

Jan. $16 / 17$

Nov. $8 / 9$

Jan. $17 / 18$

Nov. $9 / 10$

Mar. 11/12

Nov. $10 / 11$

Apr. $29 / 30$

Nov. $25 / 26$

May $27 / 28$

Nov. $27 / 28$

June 9/10

Nov. 30/Dec. 1

June 28/29

Dec. $10 / 11$

Sept. 5/6

Dec. 20/21

*Sept. $16 / 17$

oct. $22 / 23$

oct. $23 / 24$

oct. $25 / 26$

Dec. $2 / 3$

Dec. $17 / 18$

* Data used in this publication. 
TABLE II

Values for 6300 A. [Megill, 1959]

$\begin{array}{ccc}\begin{array}{l}\text { Zenith } \\ \text { angle }(z)\end{array} & e^{\operatorname{Tm}(z)} \\ 0 & .059 & 1.095 \\ 40 & .080 & 1.126 \\ 60 & .124 & 1.200 \\ 70 & .178 & 1.290 \\ 75 & .227 & 1.416 \\ 80 & .333 & 1.665\end{array}$




\section{APPENDIX I}

There are two master data tapes - one for each year of observations. The nights recorded on the tapes are in the order listed in Table I. By using two tapes, the computer time spent in searching for a particular night is decreased considerably. It should be noted that the data have been written on the tapes in high density. As they are binary tapes, no format statement is necessary. The command to recall this information is: READ TAPE N, K, NSTA, NCLR, NYR, MO, NDAY, NH, NM, RAVG, ZEN, RN, ( $(A R C(I, J), I=1,360), J=1,5)$

where

$\mathbb{N}$ - is the designated tape unit.

K - a fixed point number which is either 32000 or zero. When a zero occurs, it signifies the end of the tape. Unlike an end of file, it is possible for the user to control the tape at this point (i.e., backspace and write, exit, etc.). NSTA - this is a code used for identifying the station which took the data. The number assigned the Rapid City Observation Station was 4. This number is arbitrary and may be changed without affecting the results of the mapping program. NCLR - As there were three lines being observed ( $5577 \AA$, $5893 \AA$, and the $6300 \AA$ ), it was necessary to identify the wavelength being analyzed. In this instance the red line $(6300 \AA)$ was assigned the fixed point number 3 . Although only the $6300 \AA$ line is presently on the tape, the program is set up to include the green line and the sodium line. In order to get the correct printout for line 
identification, the number $\underline{3}$ must be used for the red line.

NYR, MO, NDAY - three fixed point values which refer to the year, month, and the day respectively.

NH, NM - both of these values are fixed point and represent the time of the survey in hours and minutes.

RAVG - the average intensity of the sky after corrections for extinction and scattering have been made.

ZEN - the zenith intensity averaged over the whole zenith sweep. RN - a sensitivity reading taken from the instrument at Rapid City. This was for information only and not used in the calculations for mapping.

$A R C(I, J)$ - this array contains the values of survey for every degree of azimuth ( $I=1,360$ ) for each zenith angle value $(J=1,5)$. The zenith angles correspond to the " $J$ 's" as follows:

$\begin{array}{lc}\text { J } & \text { Zen. Angle } \\ 1 & 80 \\ 2 & 75 \\ 3 & 70 \\ 4 & 60 \\ 5 & 40\end{array}$

Off scale values appear as $2 \times 10^{6}$ on the tape and are printed as +'s. Unreliable values appear as -1000 on the tape and are printed as $\mathrm{X}$ 's. The original program was written for the IBM 7090 computer. 


\section{REFERENCES}

Barbier, D., Ann. Geophys. 14, 334 (1958)

Cole, K., J. Geophys. Res. (in press, April 1965 issue).

Dalgarno, A., Planet. Space Science (in press).

King, G. A. M., and F. E. Roach, J. Research NBS, 65D, 129 (1961).

Marovich, E., and F. E. Roach, J. Geophys. Res. 68, 1885 (1963).

Megill, L. R., Ph.D. Thesis, Univ. of Colorado (1959).

Megill, L. R., M. H. Rees, and L. K. Droppleman, Planet. Space

Science, 1ㅡ, 45 (1963).

Megill, L. R., and N. P. Carleton, J. Geophys. Res., 69, 101 (1964).

Rees, M. H., Planet. Space Science, 8, 197 (1961)

Roach, F. E., and E. Marovich, J. Research NBS 64D, 205, (1960).

Roach, F. E., and J. R. Roach, Planet. Space Science, lㅡ, 523 (1963).

Roach, F. E., and I. S. Smith, NBS Technical Note 214 (1964).

Smith, L. L. and R. B. Alexander, IQSY Instruction Manual No. 5 (1963). 


\section{FIGURE CAPTIONS}

Figure 1. A map relating the distance on the earth's surface to the corresponding zenith angle assuming the height of emission is $400 \mathrm{~km}$.

Figure 2. Radial distances along the earth's surface for various heights as a function of the zenith angle. 


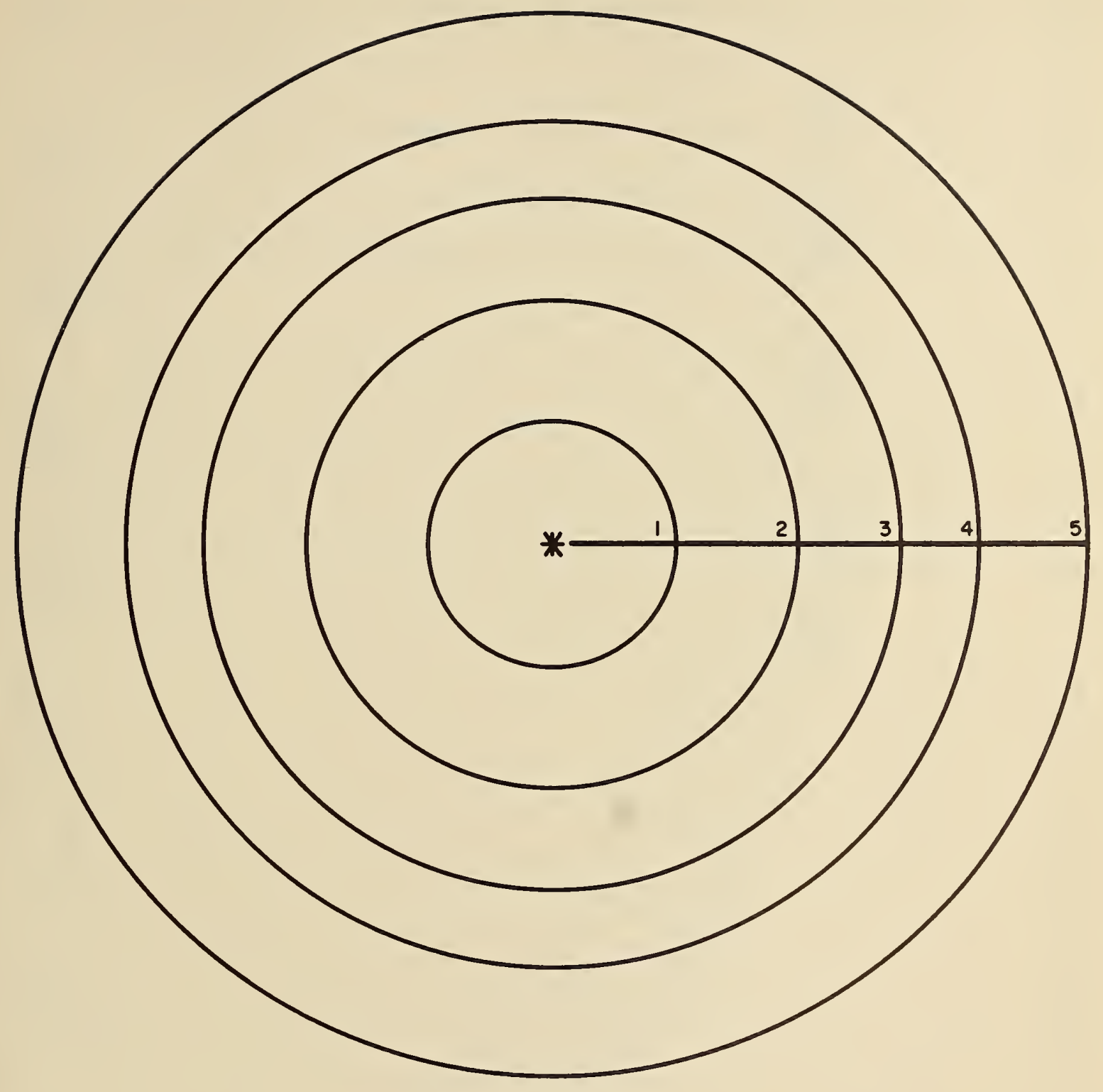

ZENITH

ANGLE

STATION

40

60

70

75

80
RADIAL DISTANCE

IN $\mathrm{km}$

310

603

873

1070

1340 


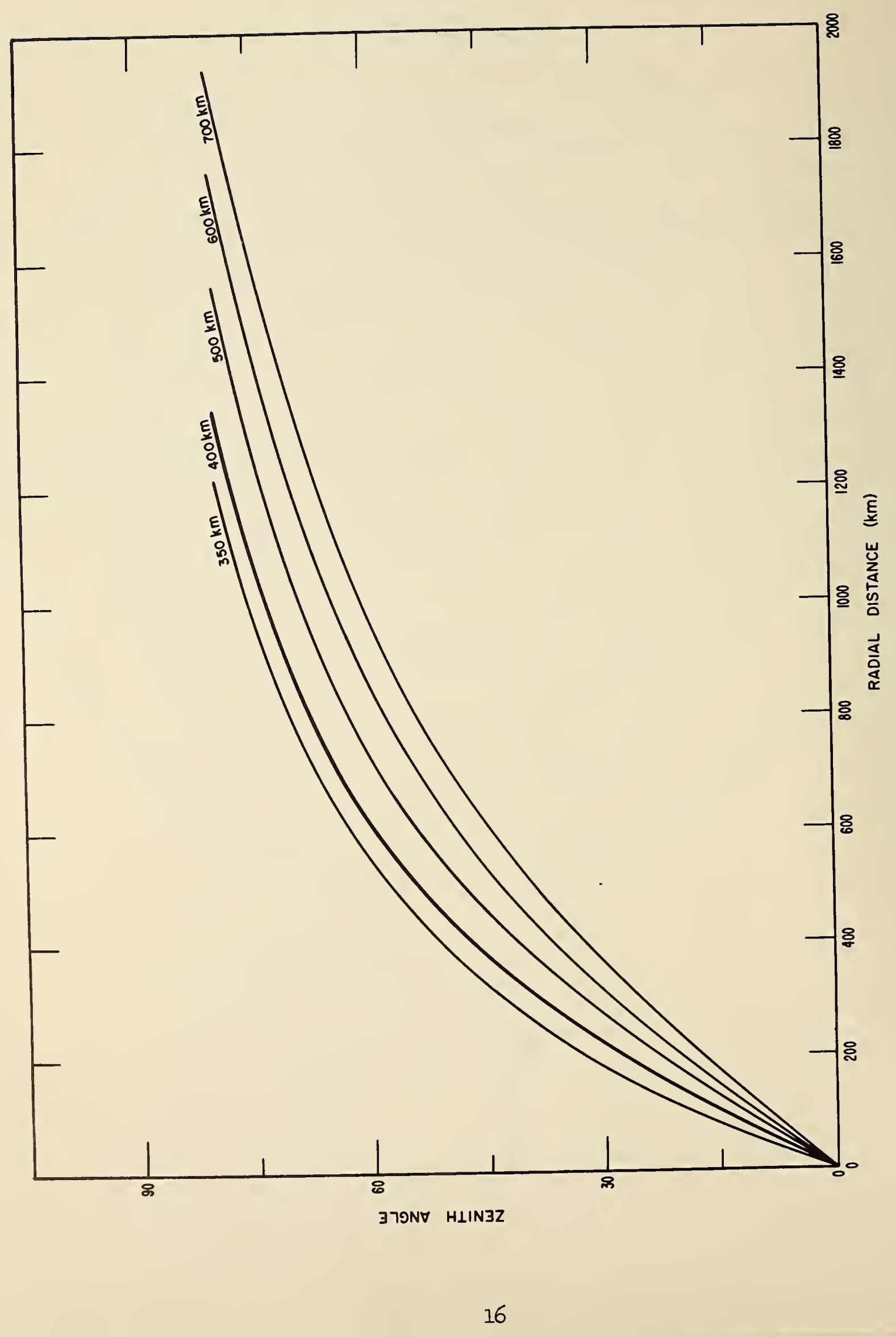




\section{DESCRIPTION OF MAPS}

Looking at the map with the legend in the upper left-hand cormer, north is at the top of the paper and east is to the right. The observing station is at the center of the circle. Zenith angles from the station and the corresponding distances on the earth's surface may be calculated as in Figure 1.

The arc is characterized by a line of higher intensities from $\approx 320^{\circ}$ to $\approx 100^{\circ}\left(0^{\circ}\right.$ at $\mathbb{N}$ and $90^{\circ}$ at $\left.\mathrm{E}\right)$. On either side of this line the intensities are lower by a substantial margin. The aurora (first quadrant) is clearly discernible by the "+'s" as the intensities are considerably greater than those of the arc. 



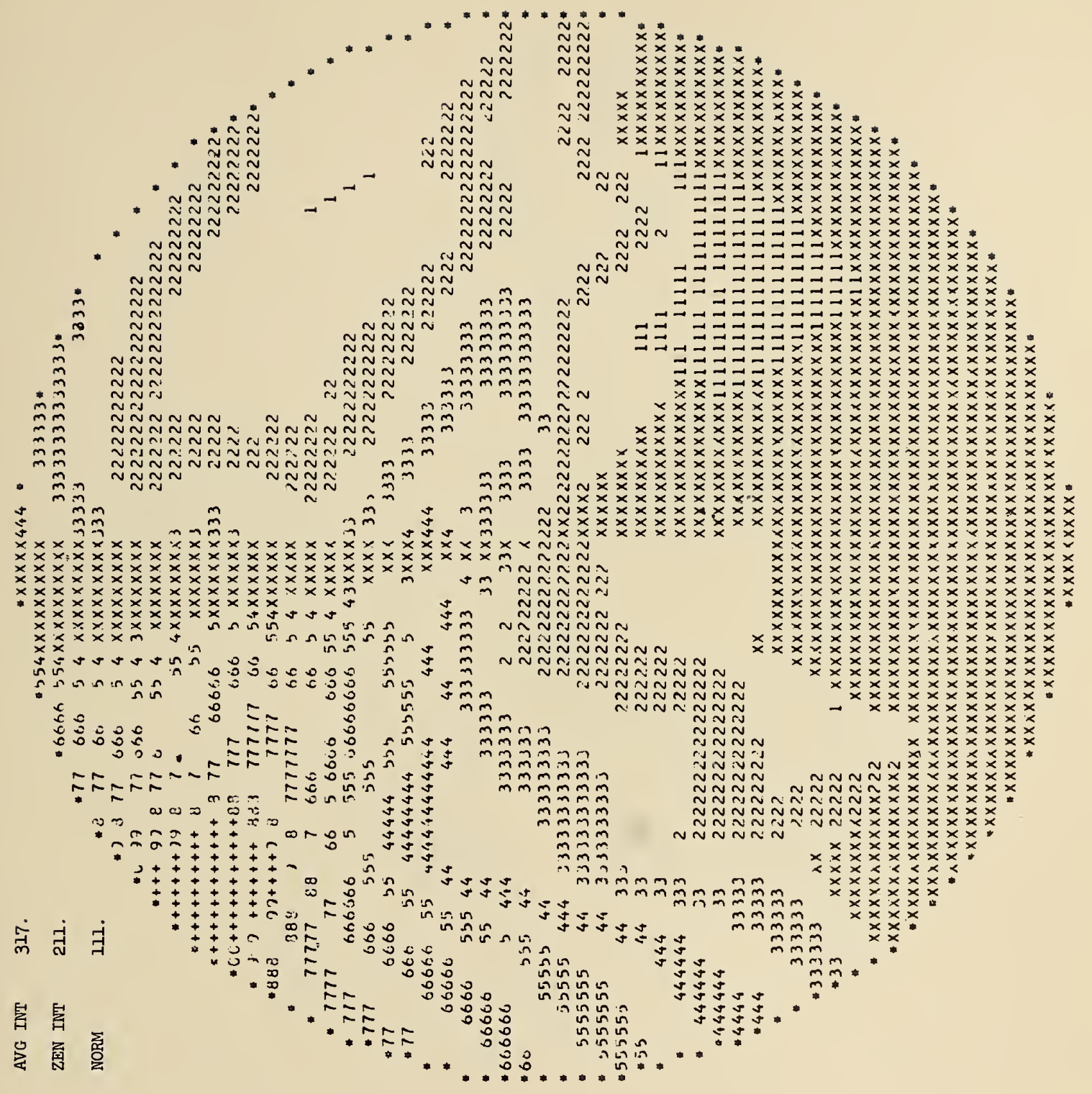





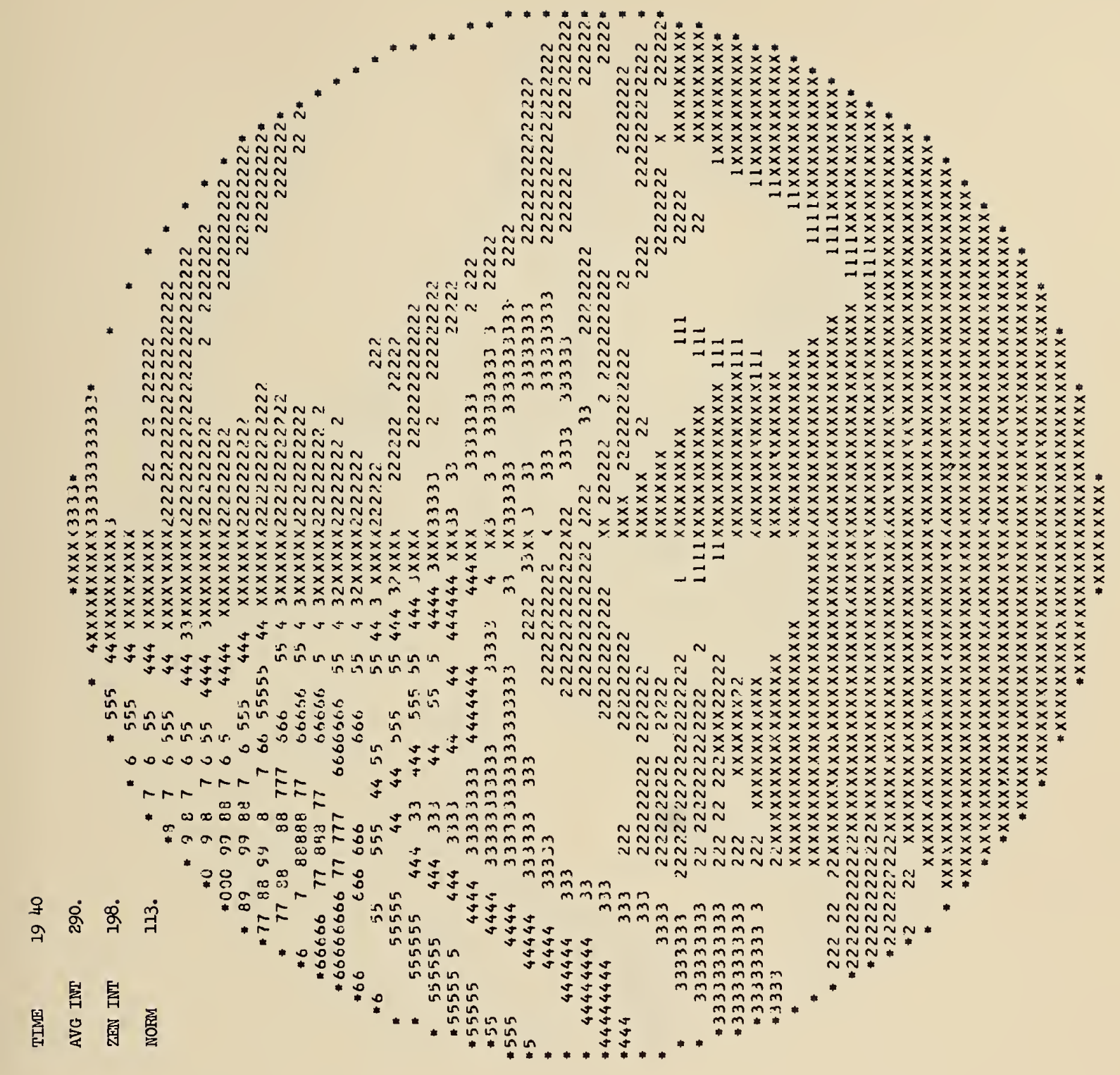





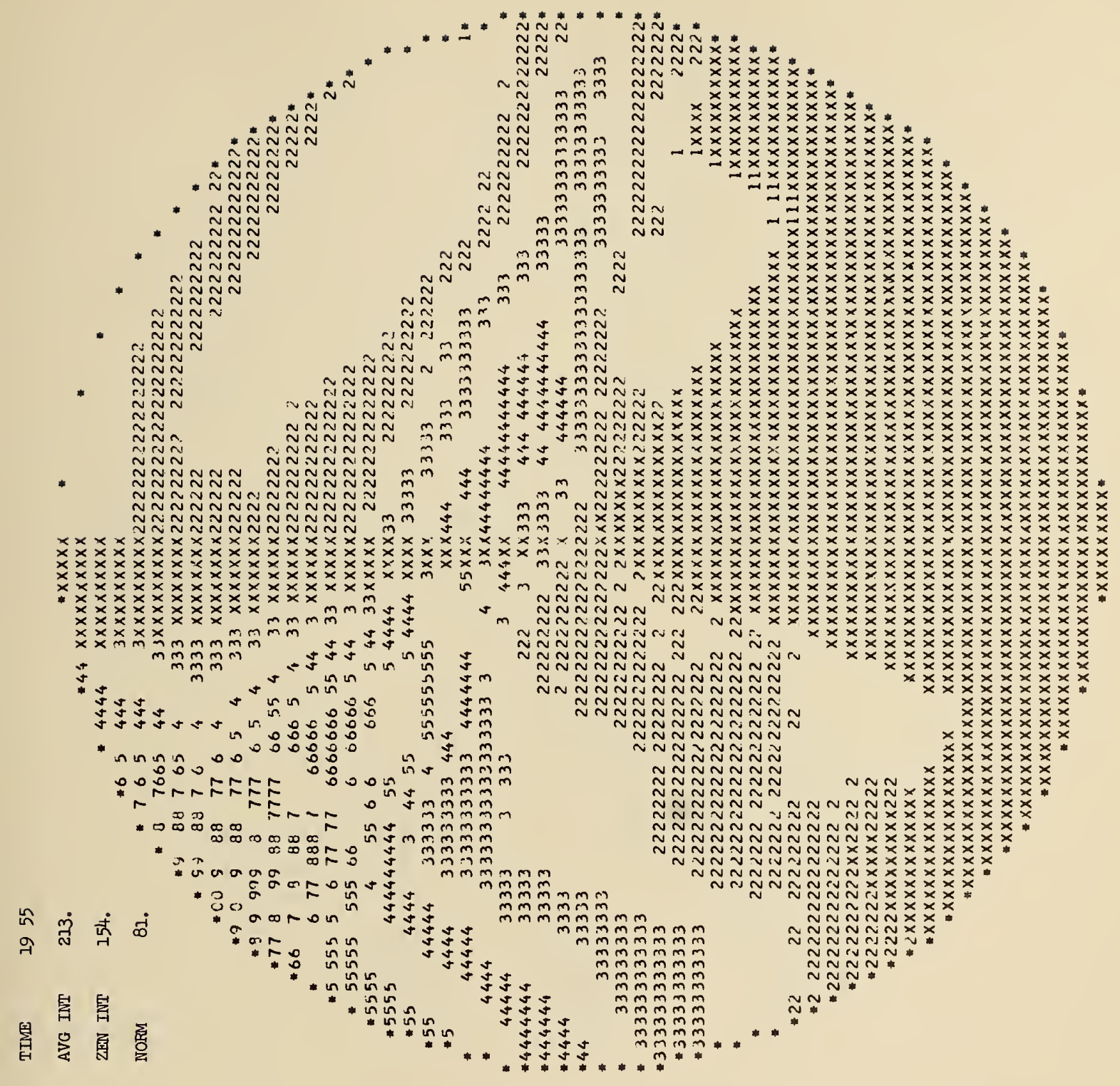





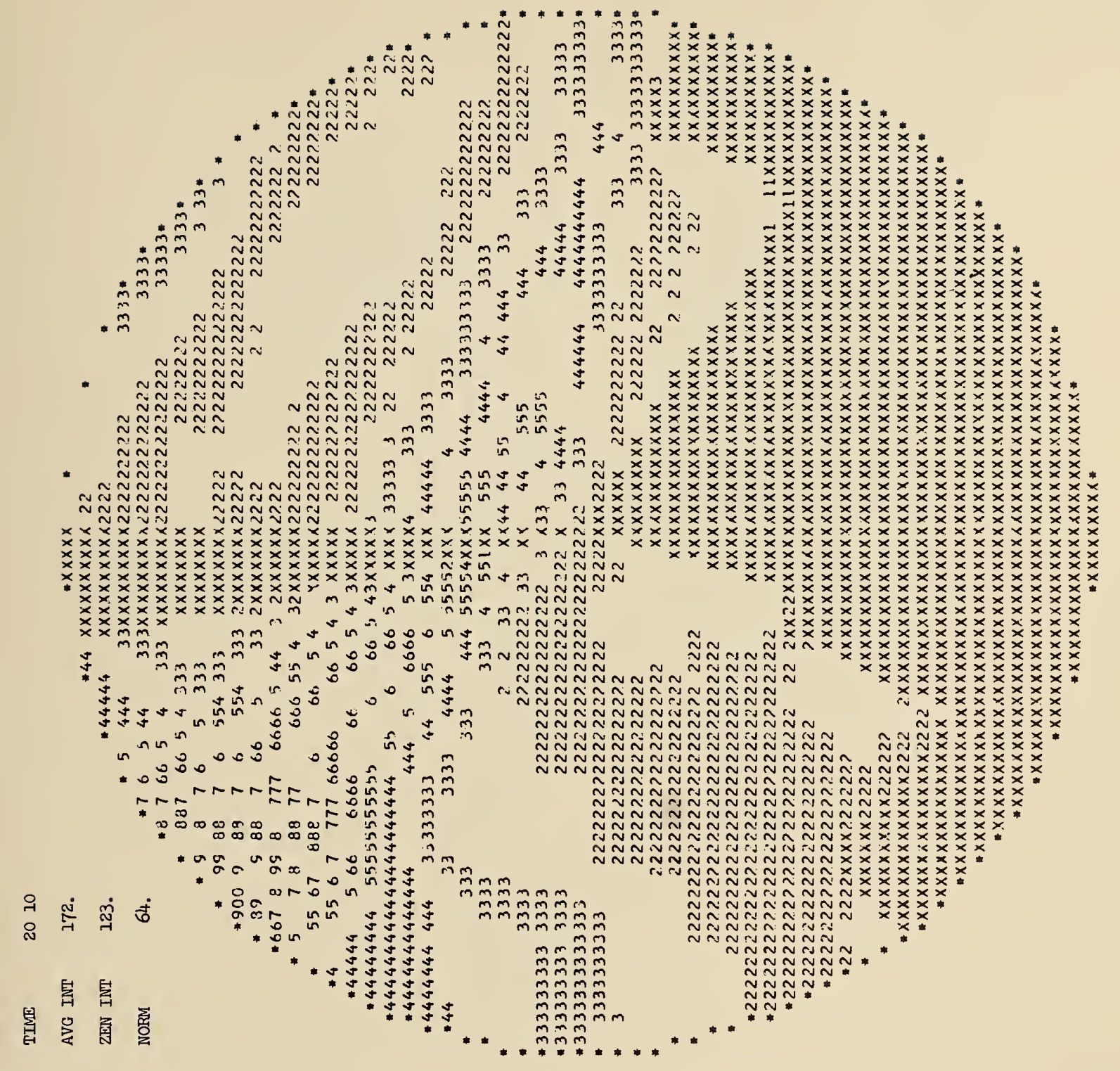





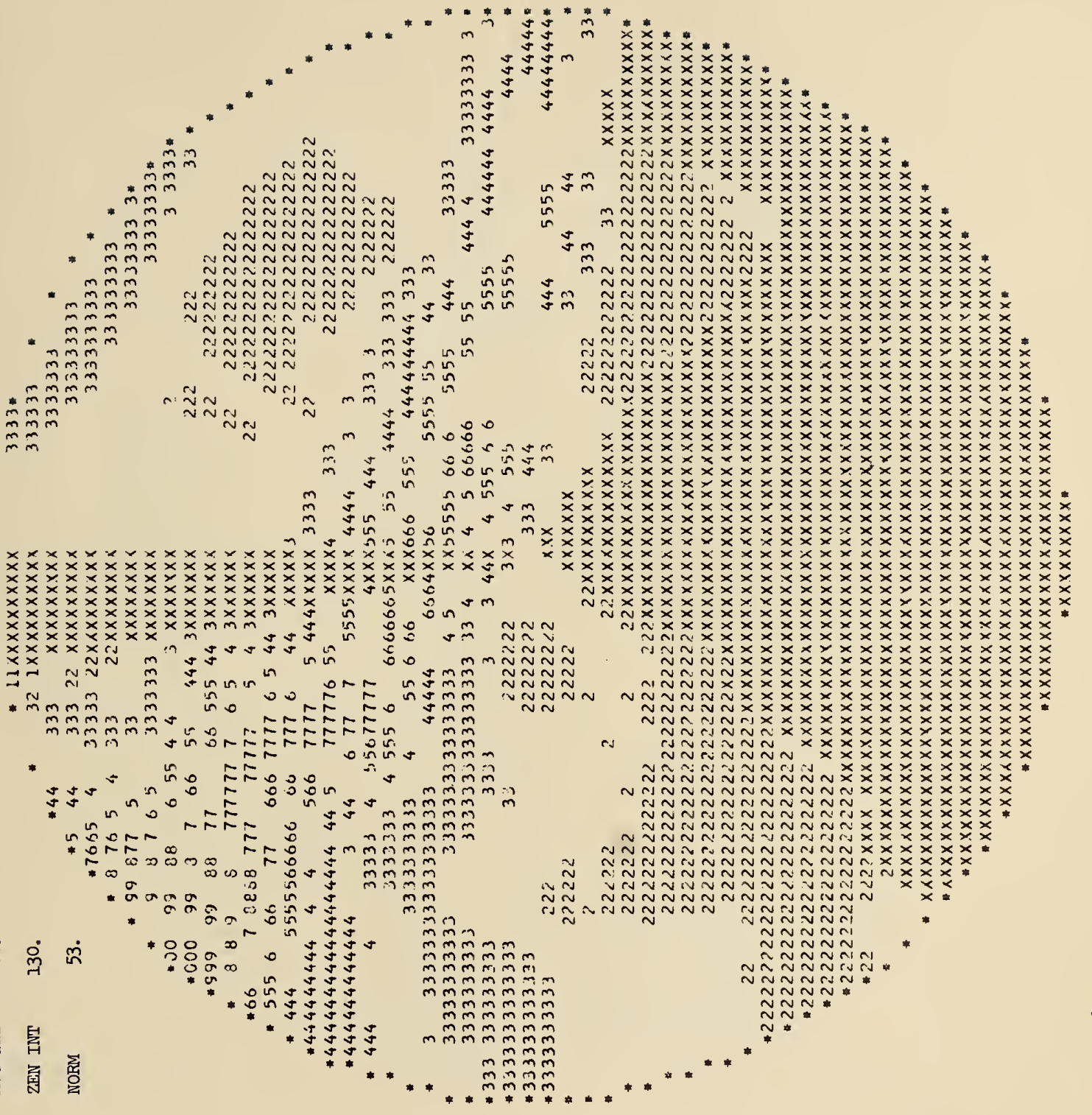





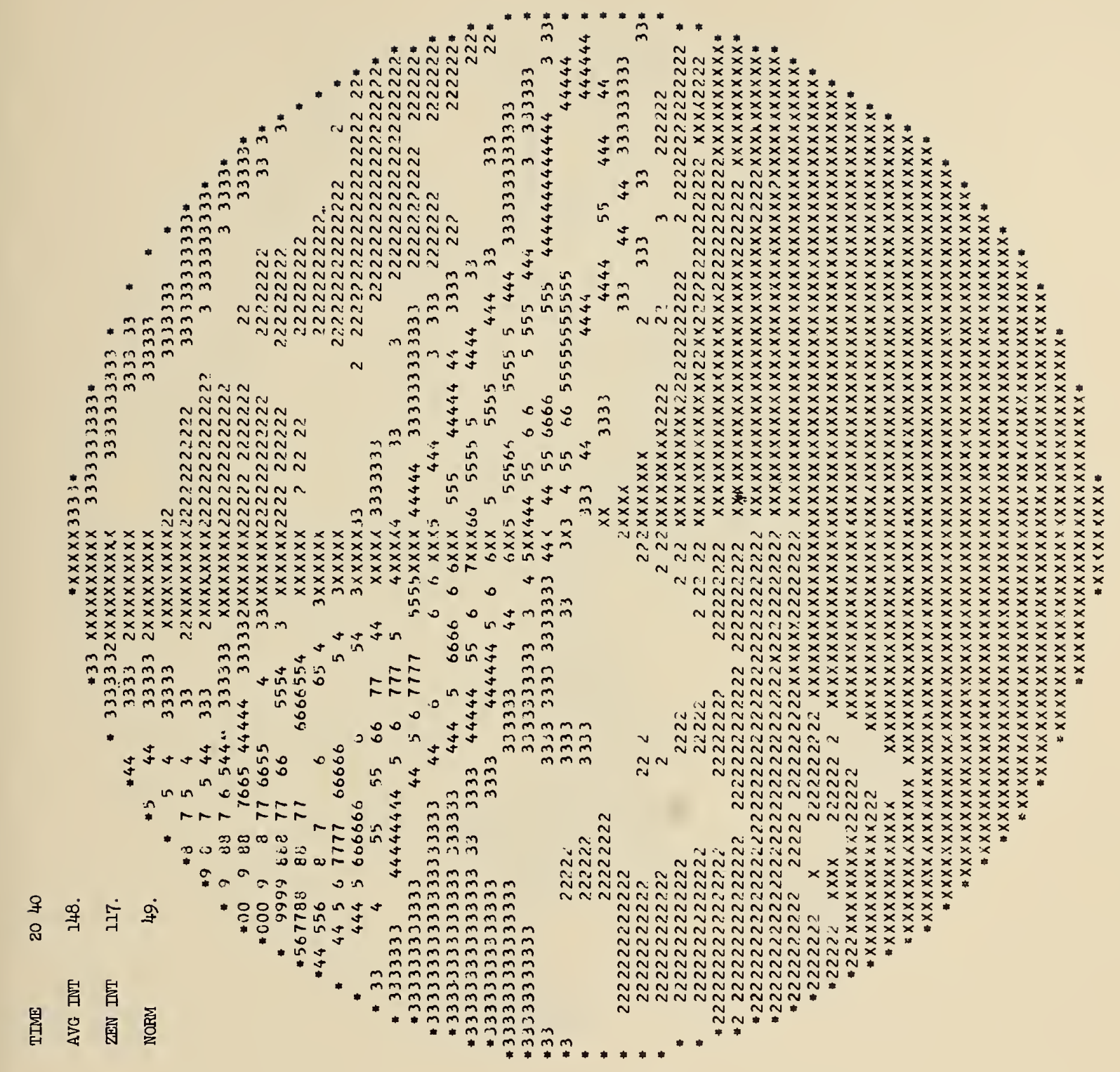





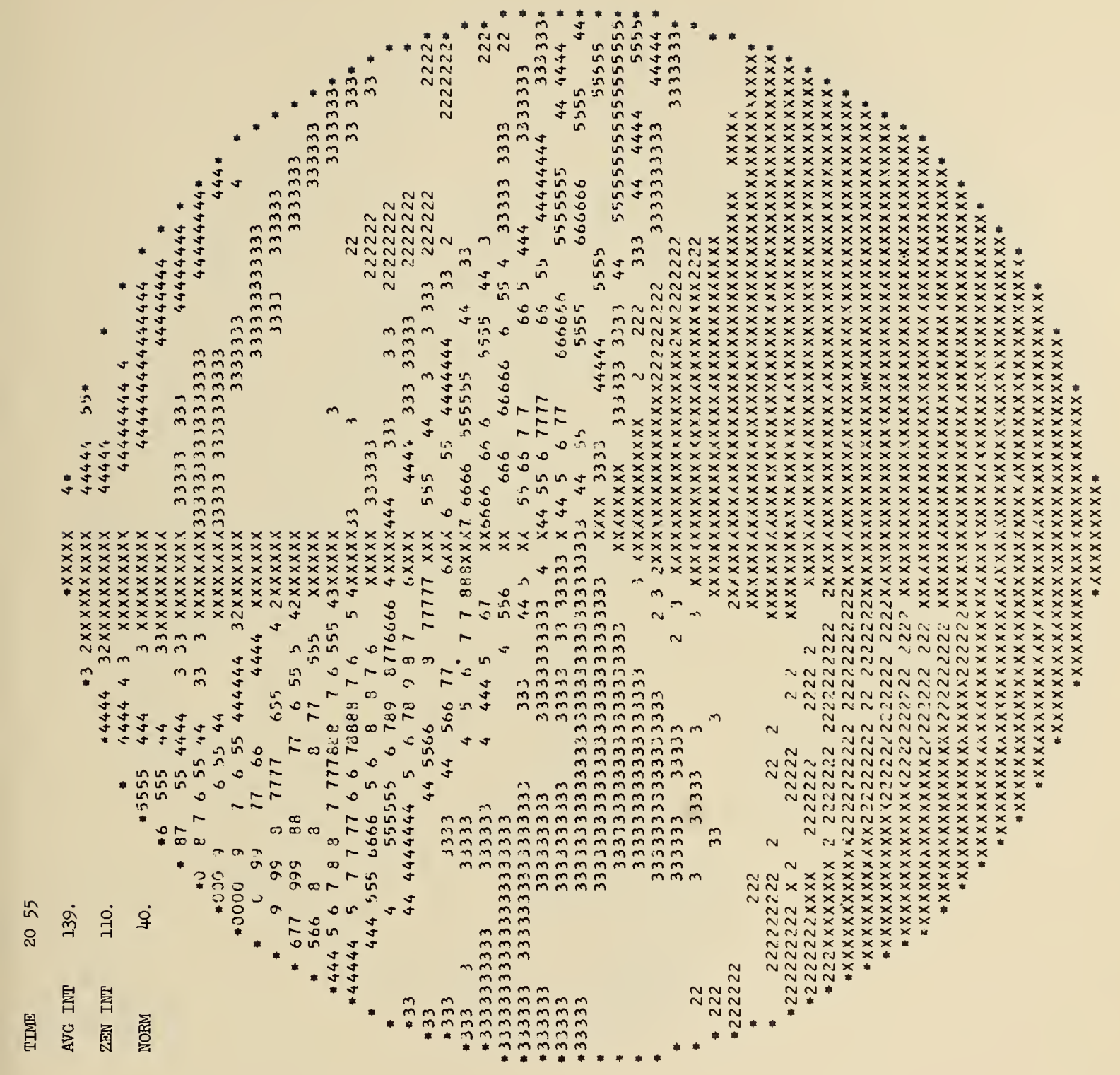





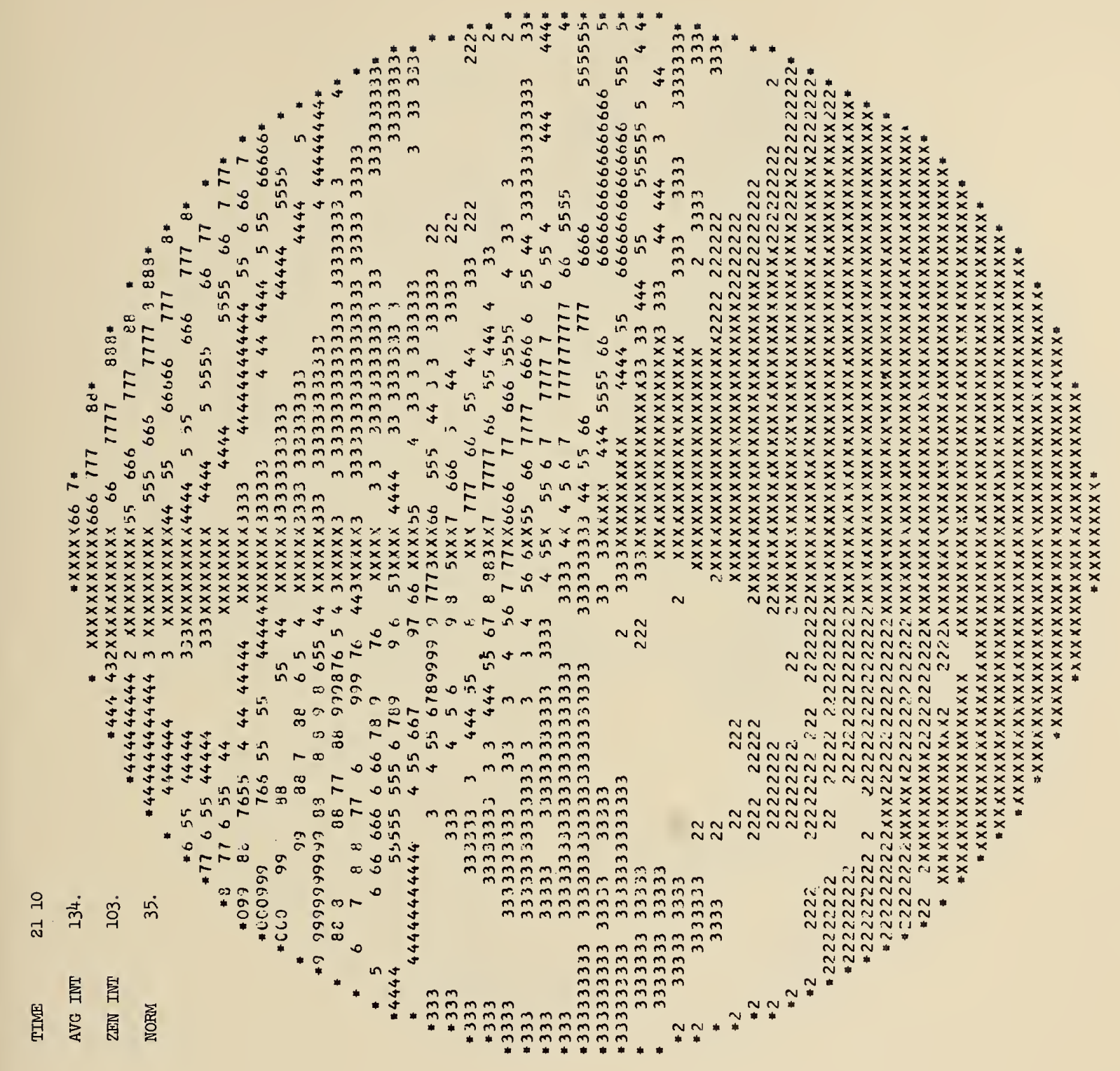





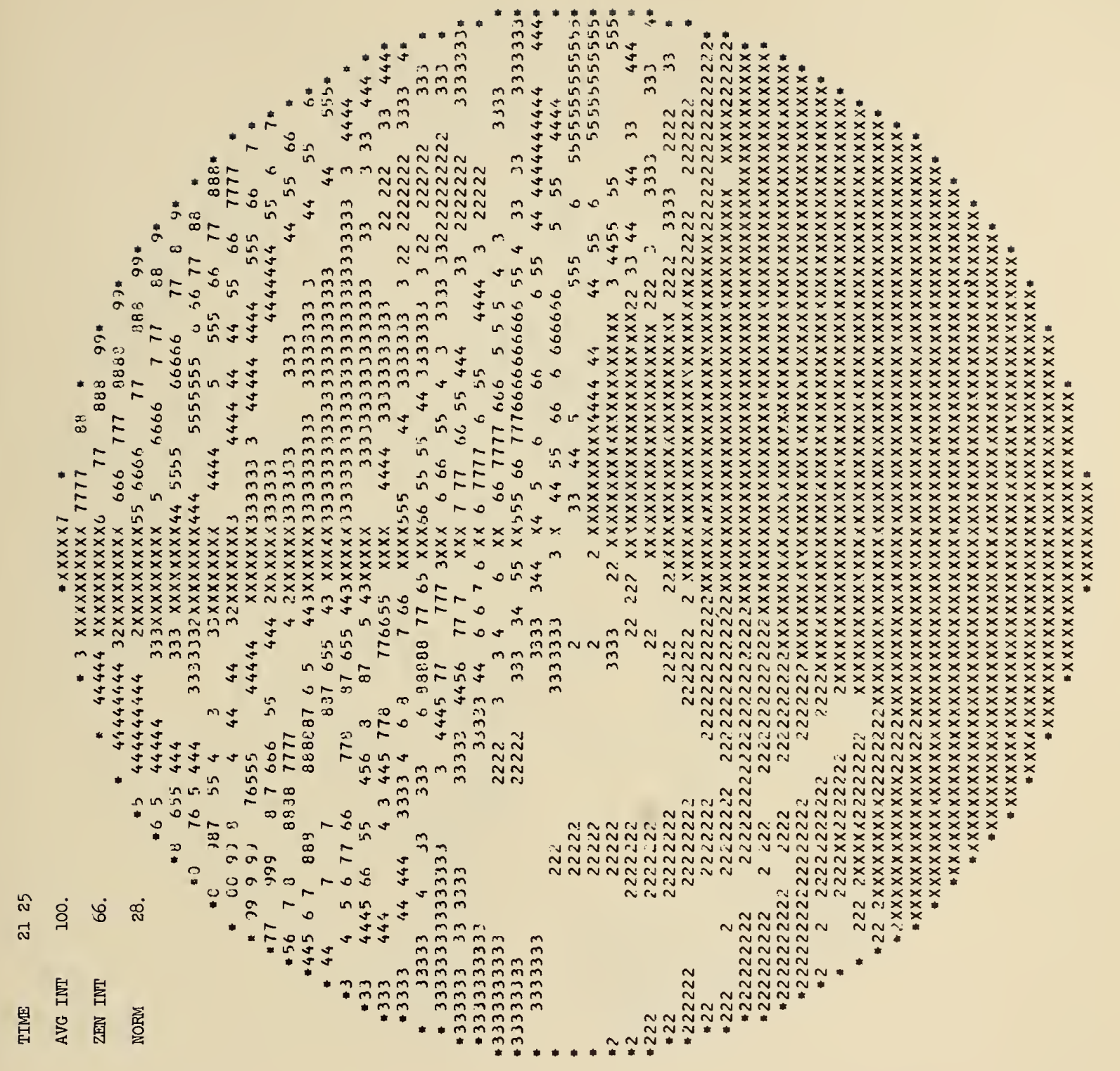





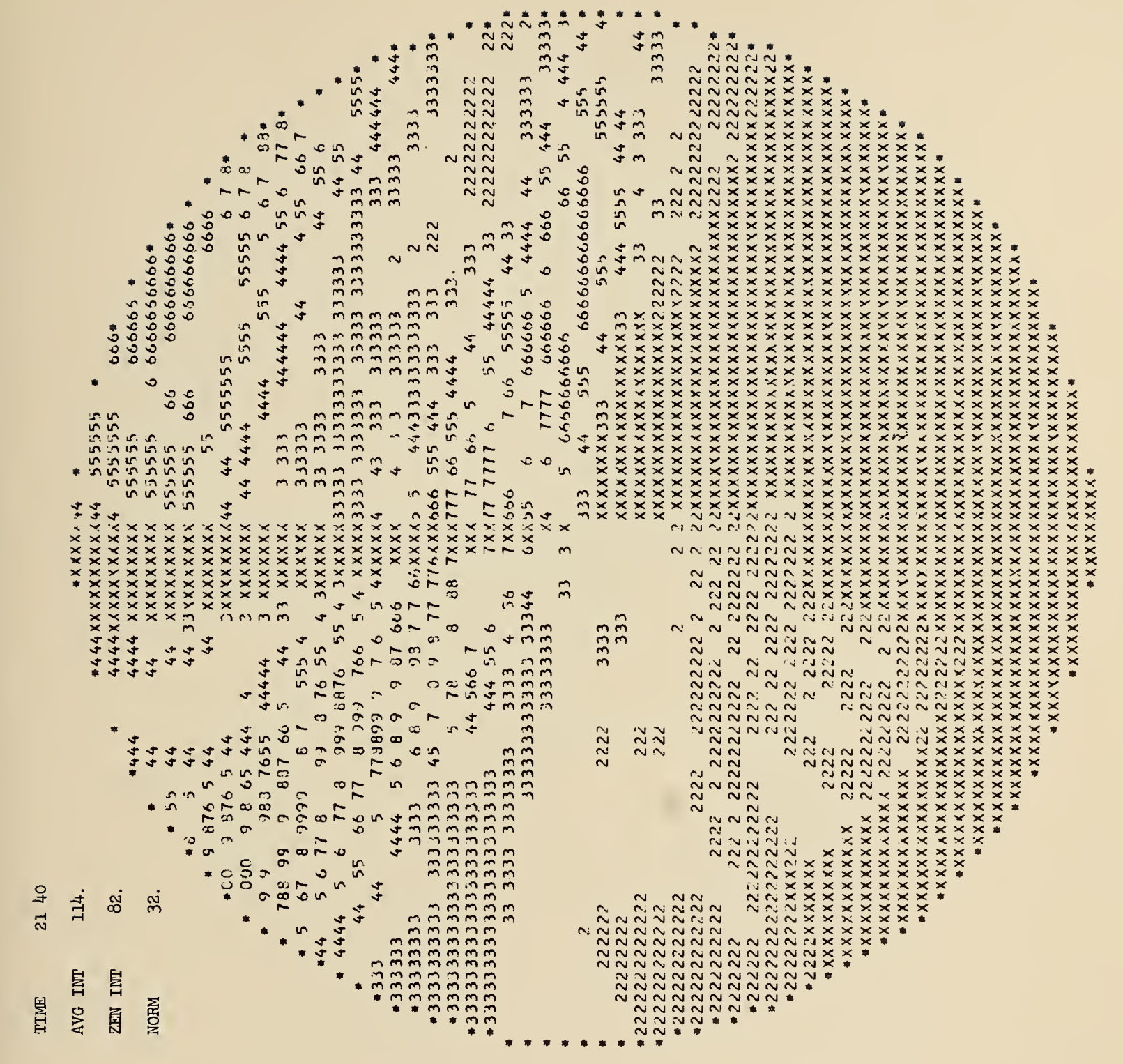





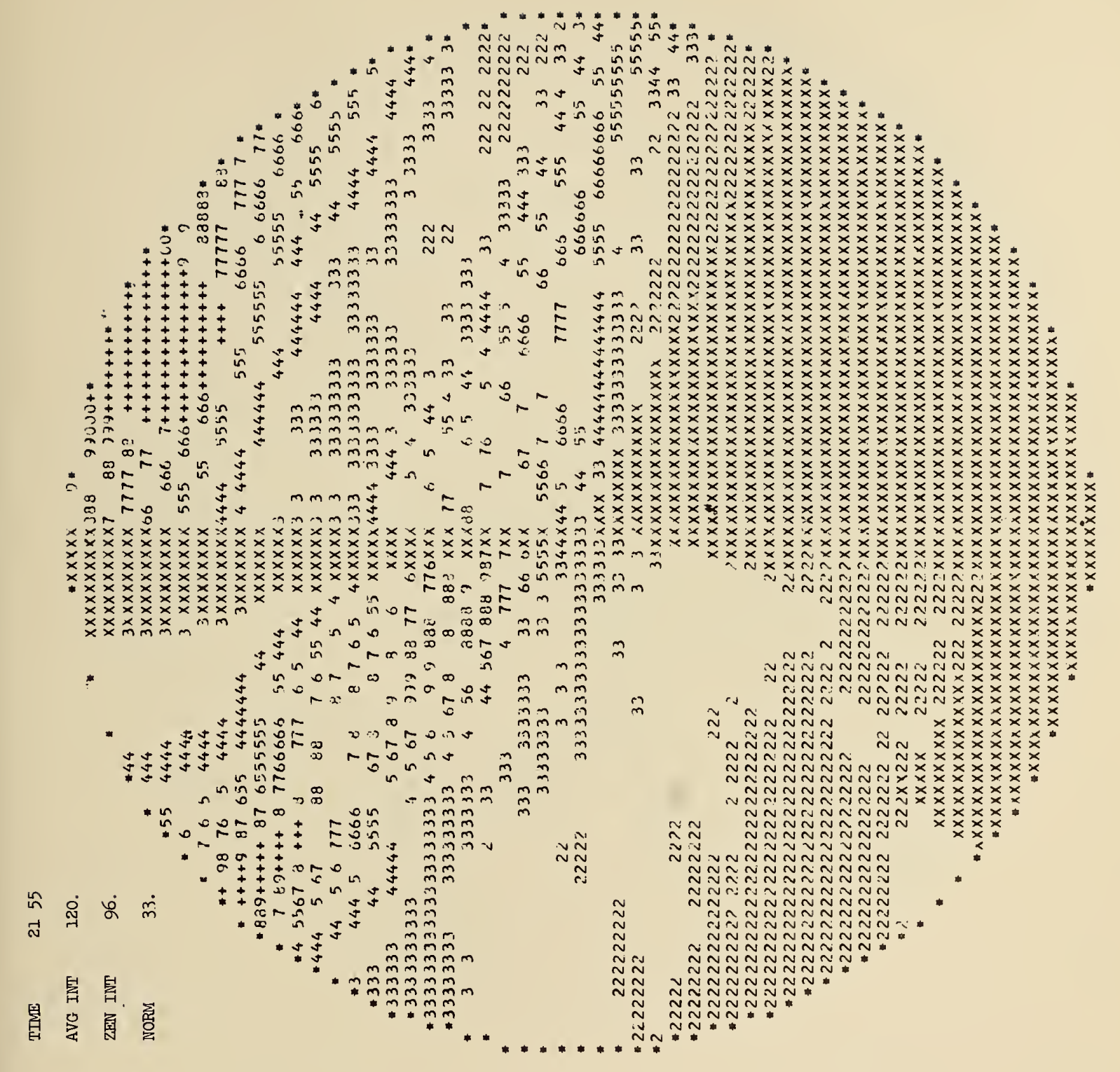





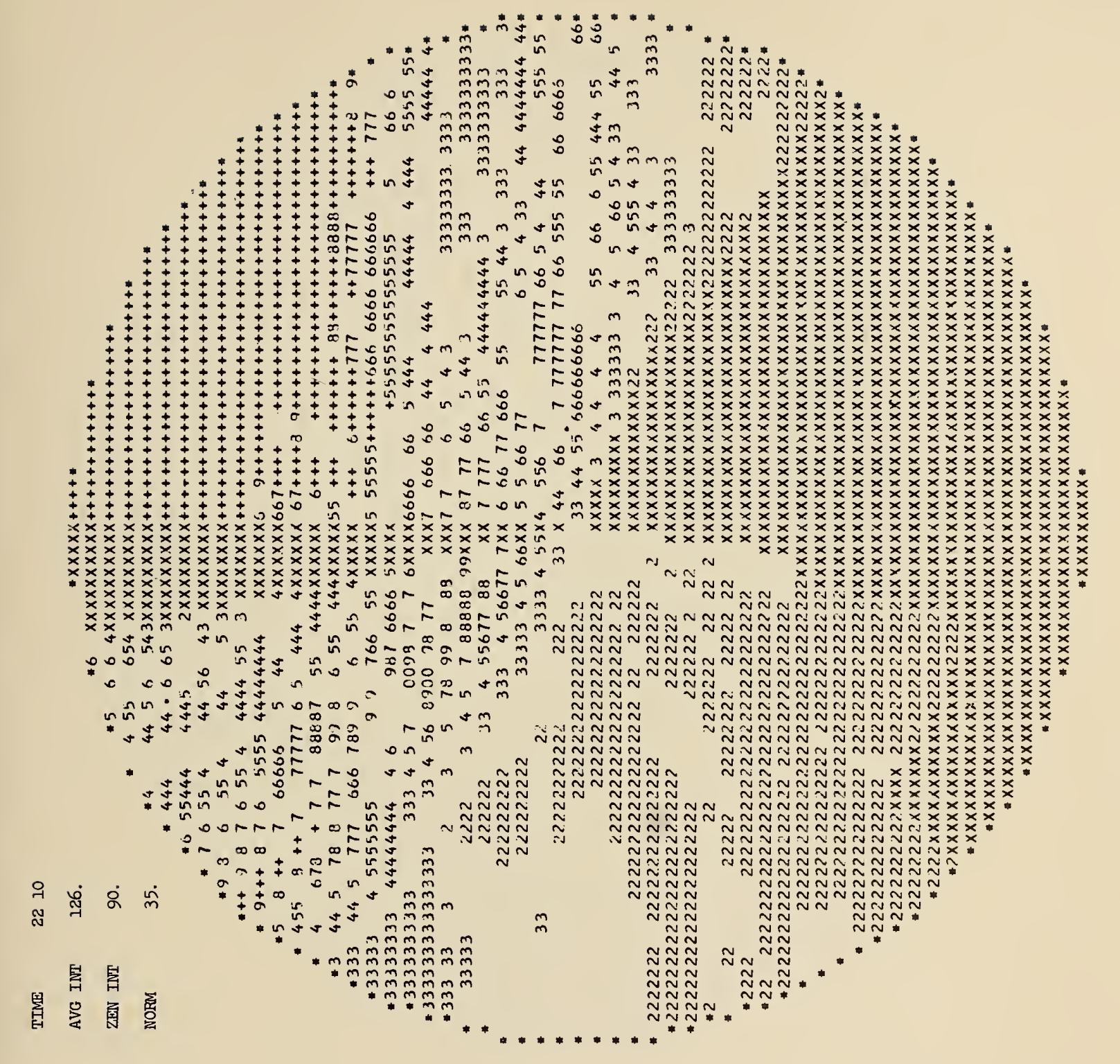





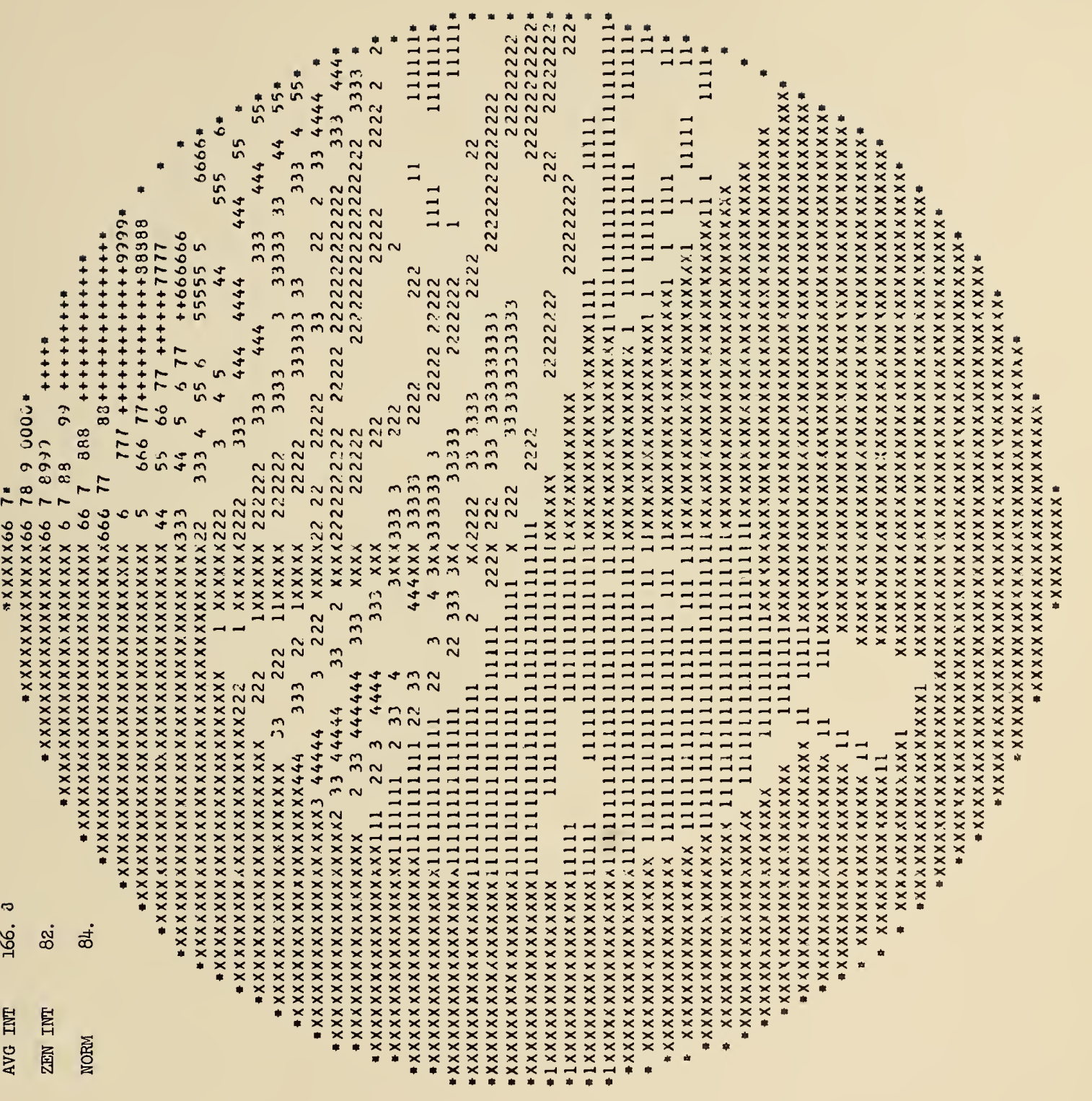





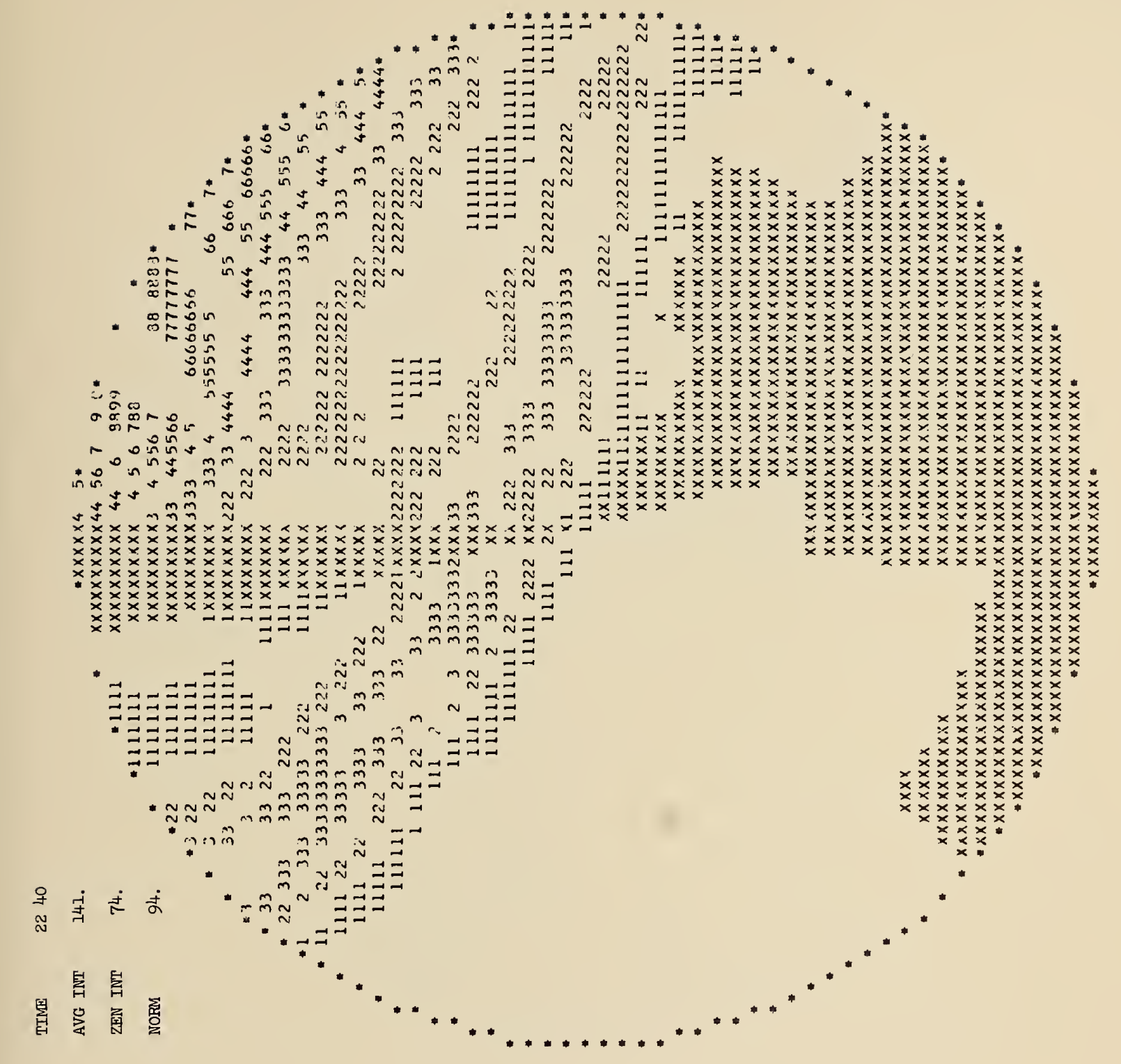





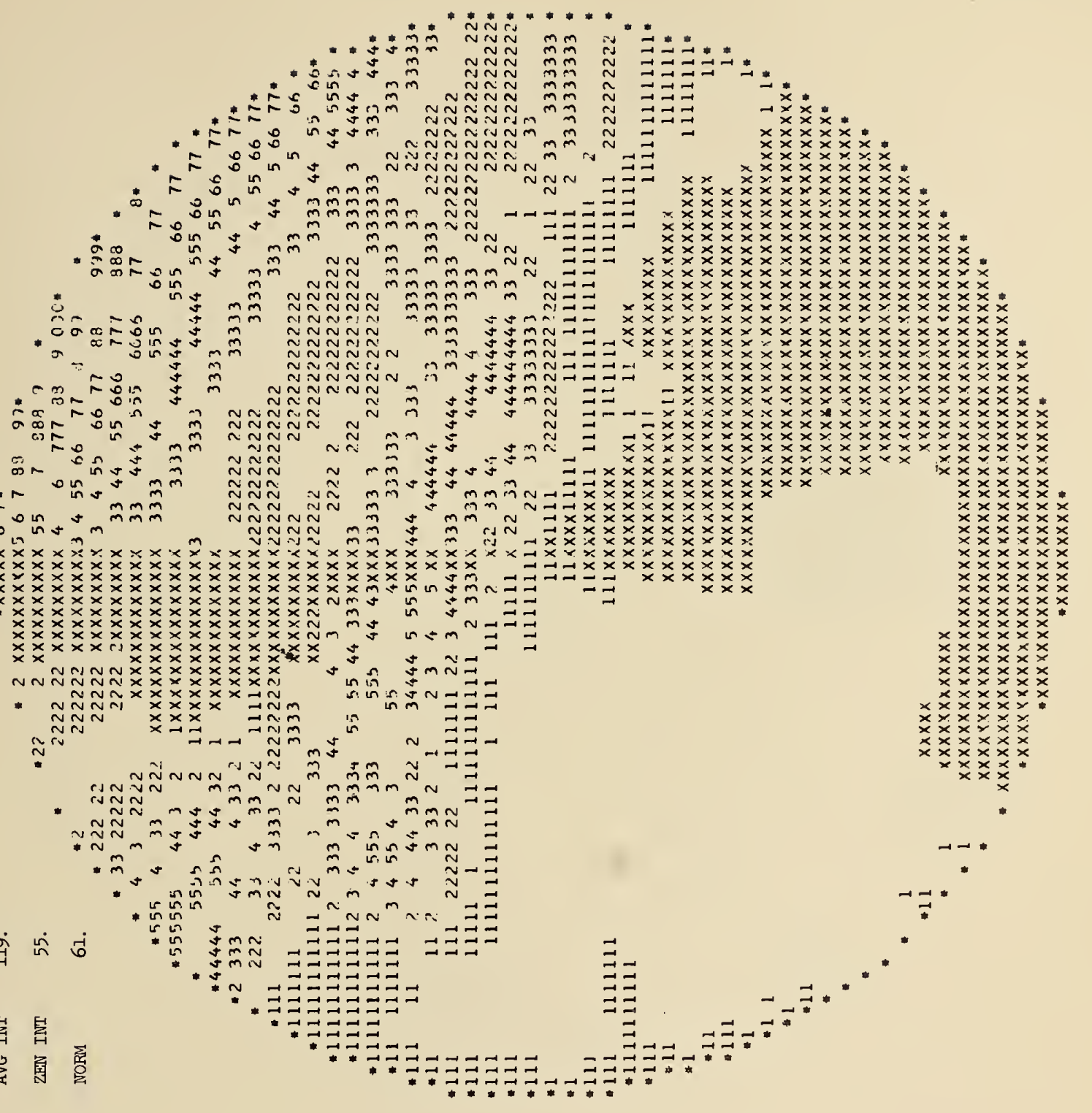





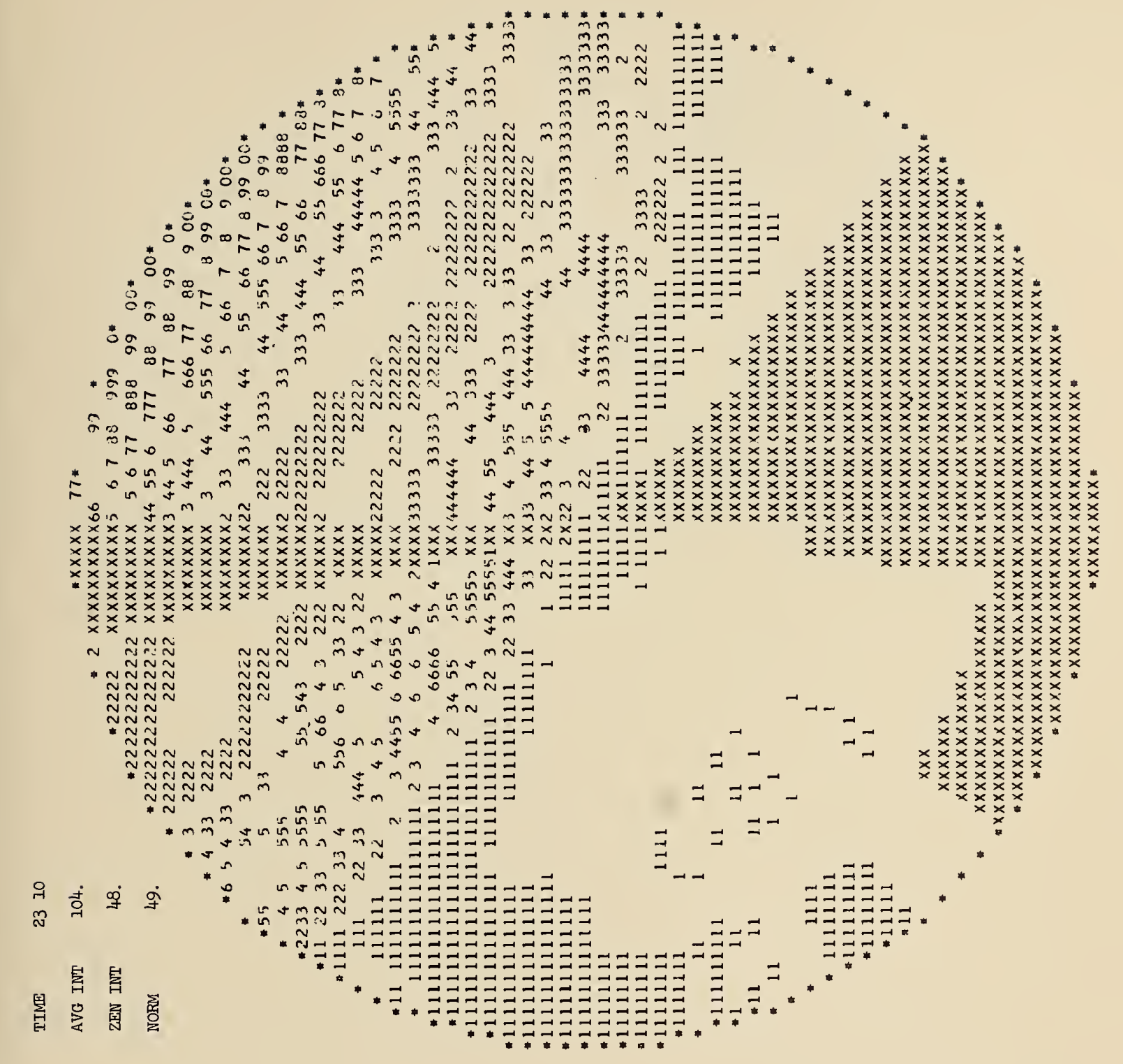





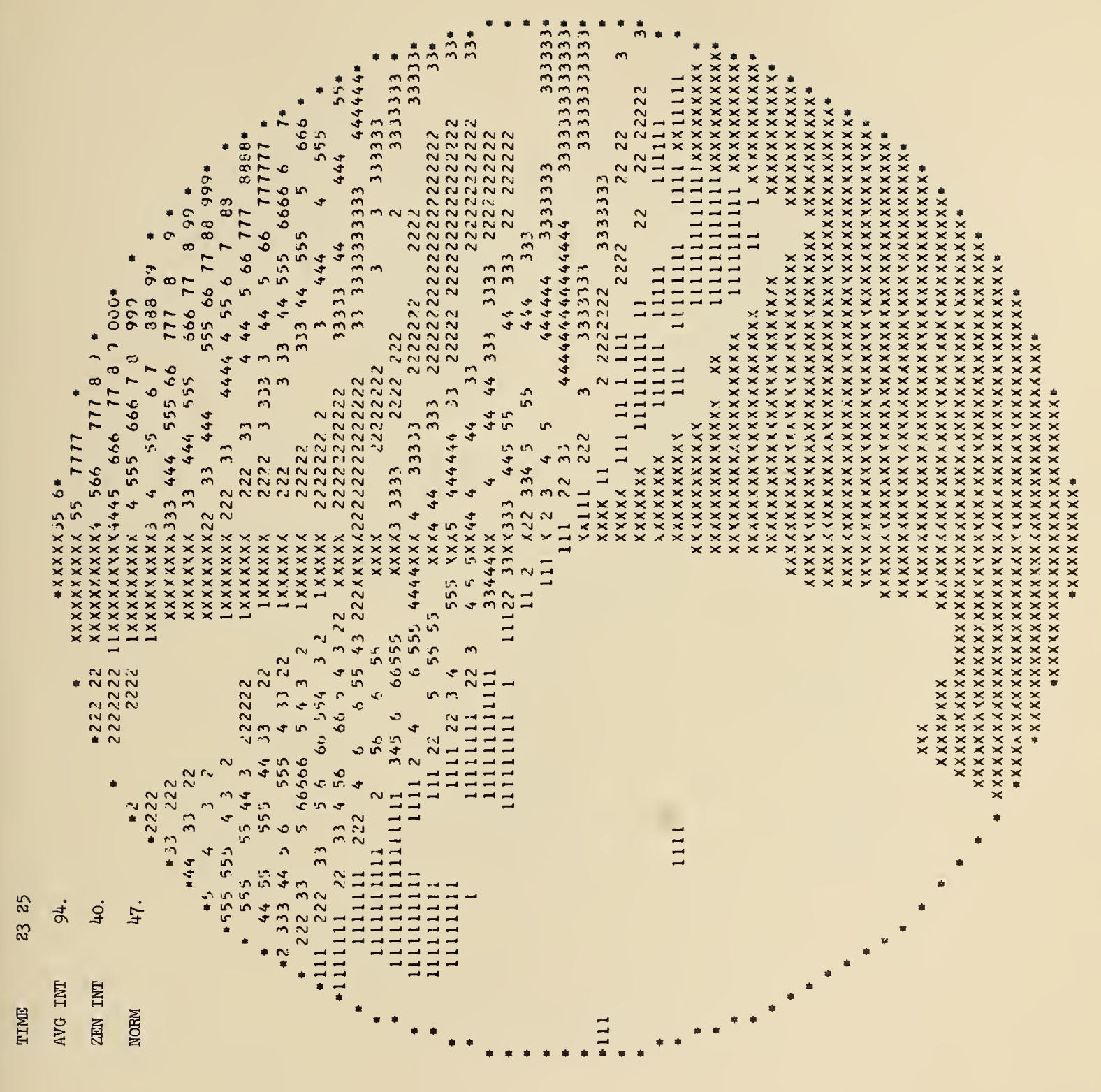

34 



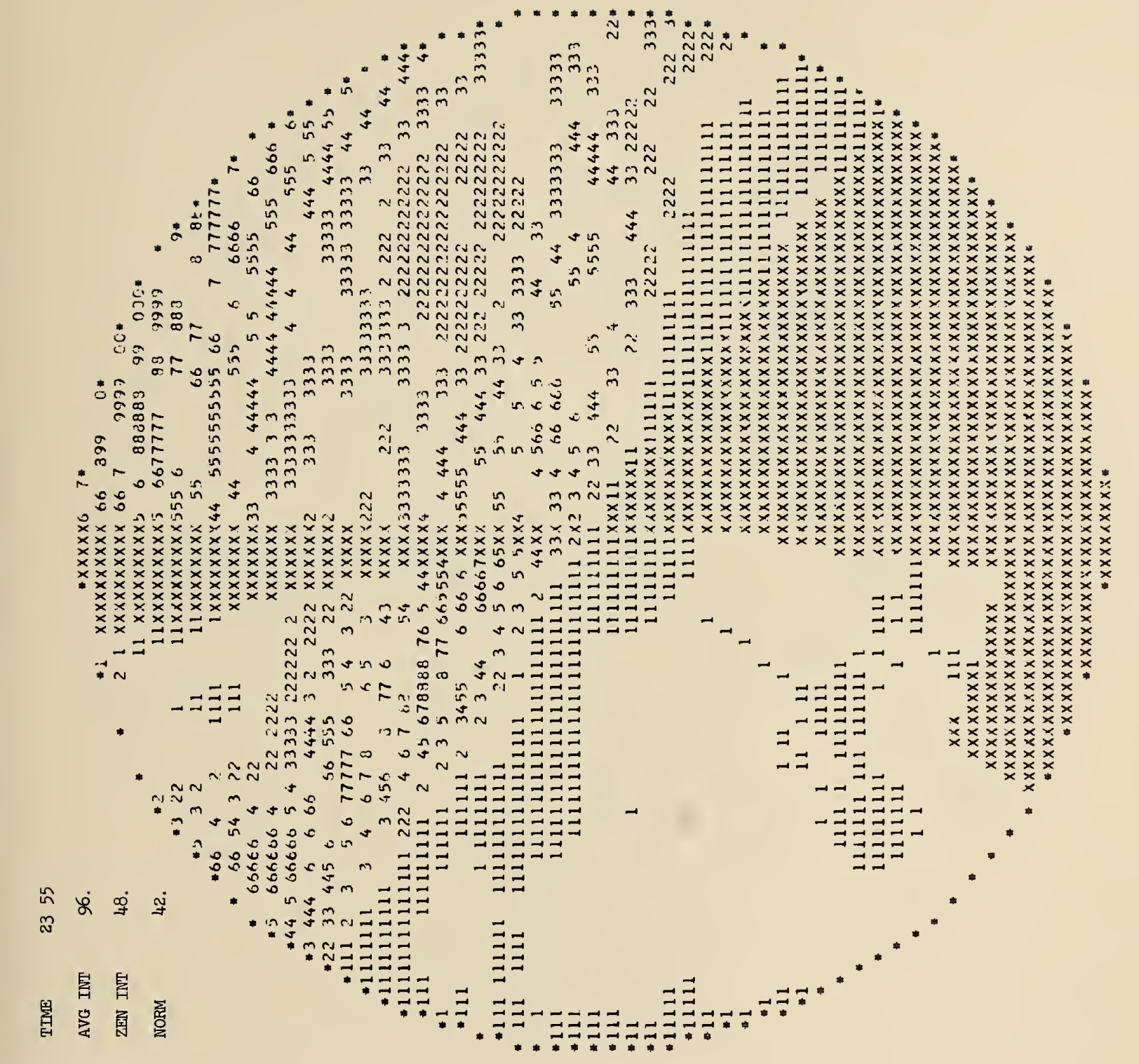





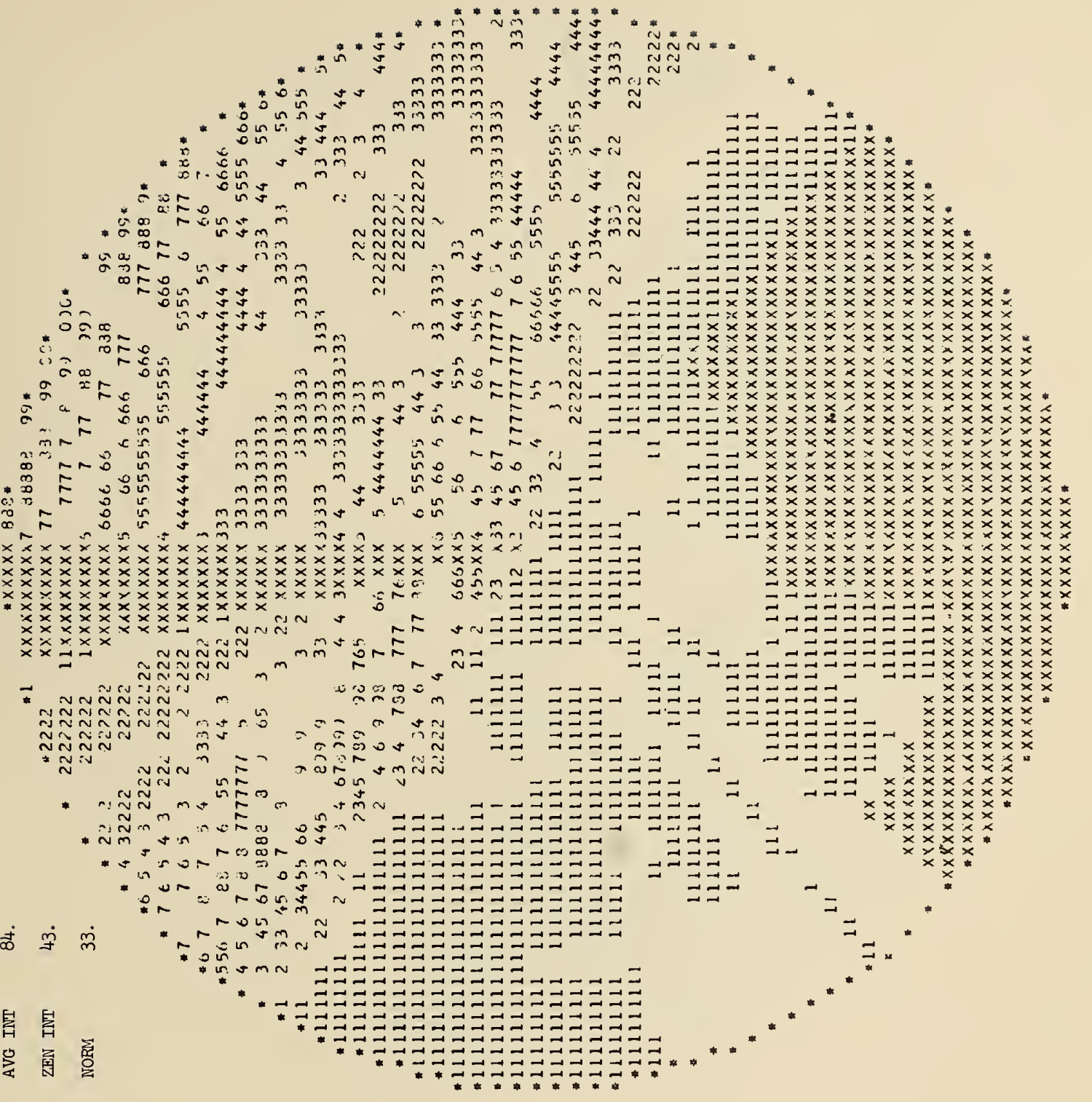





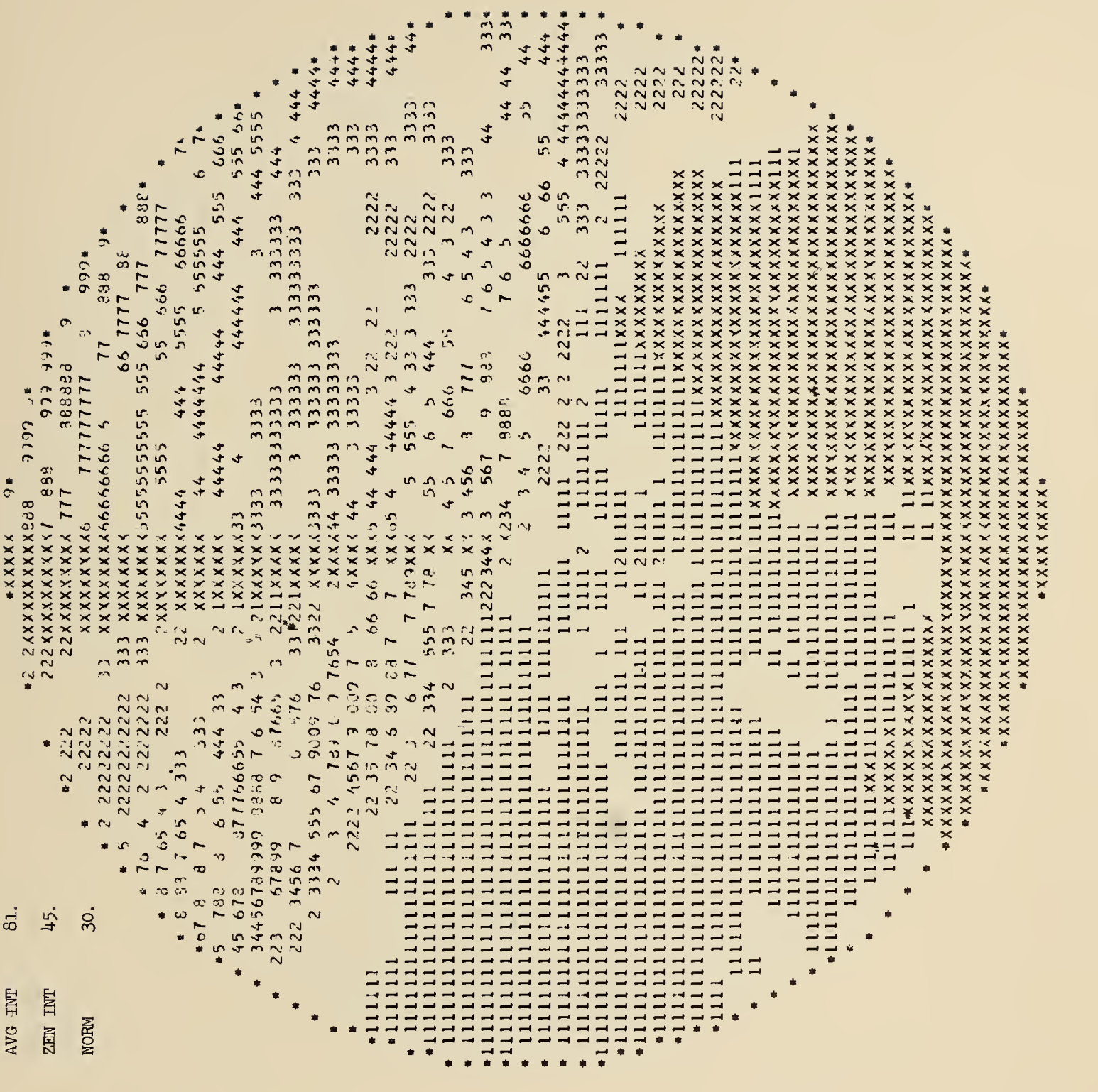





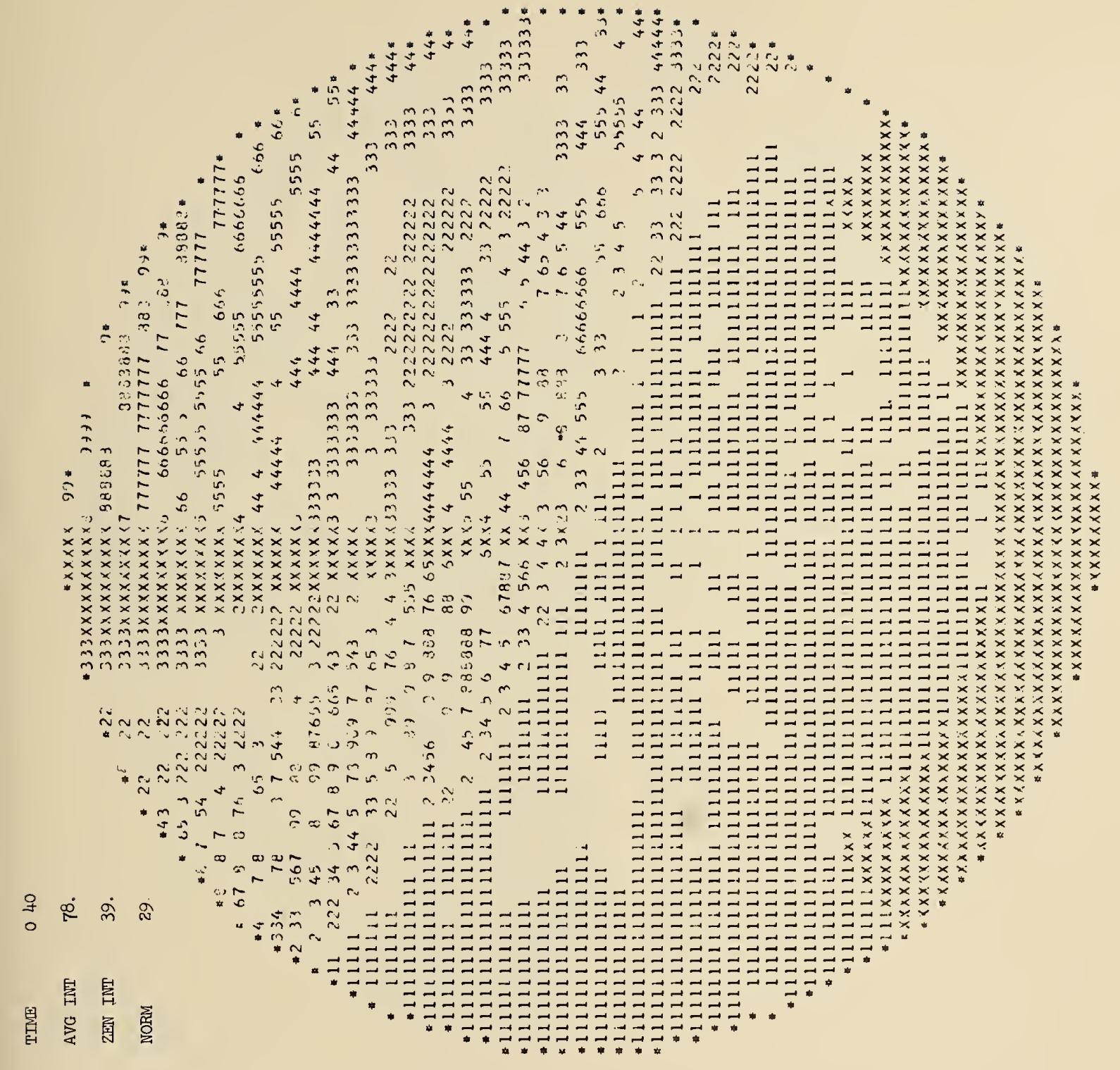





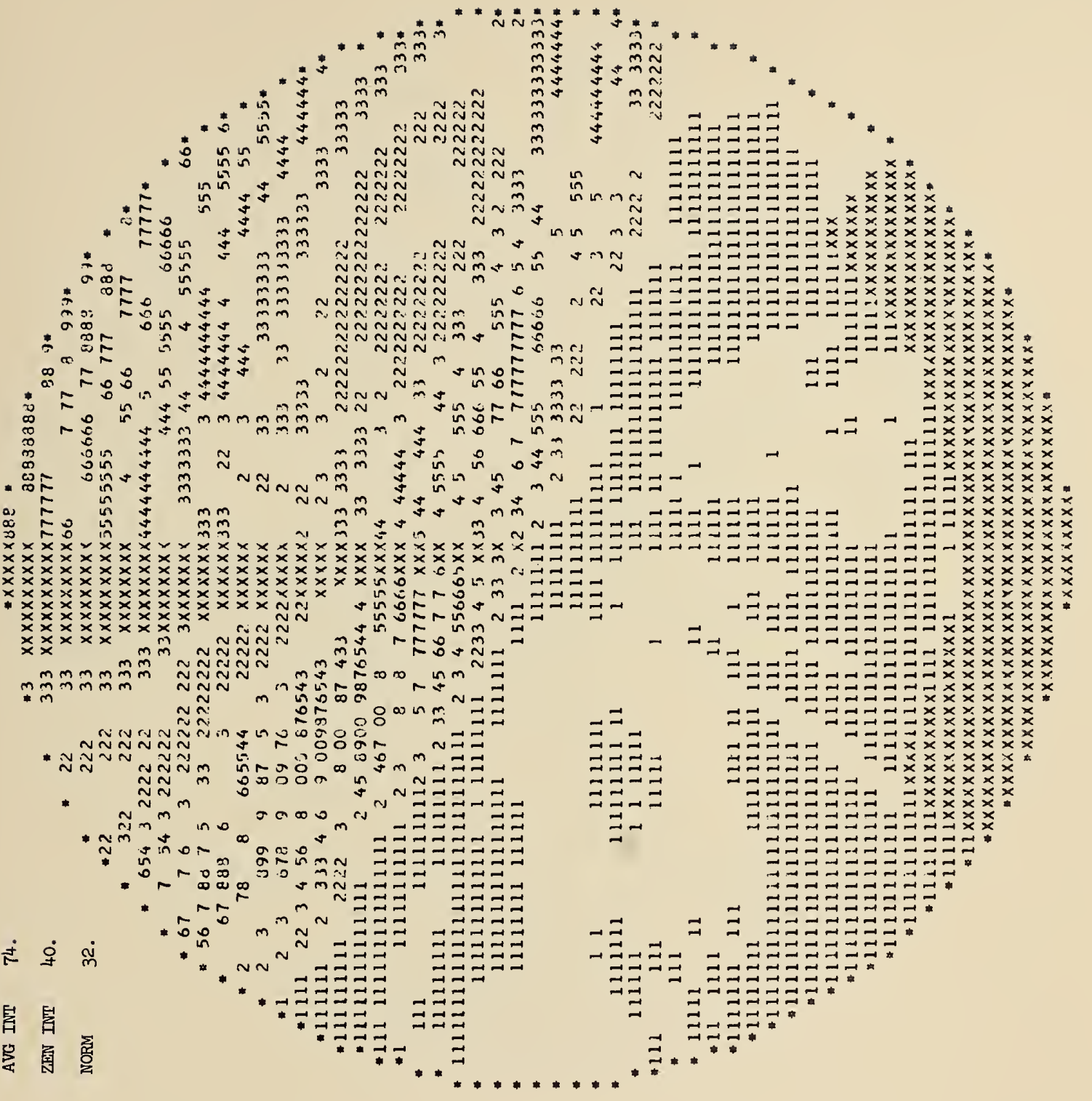





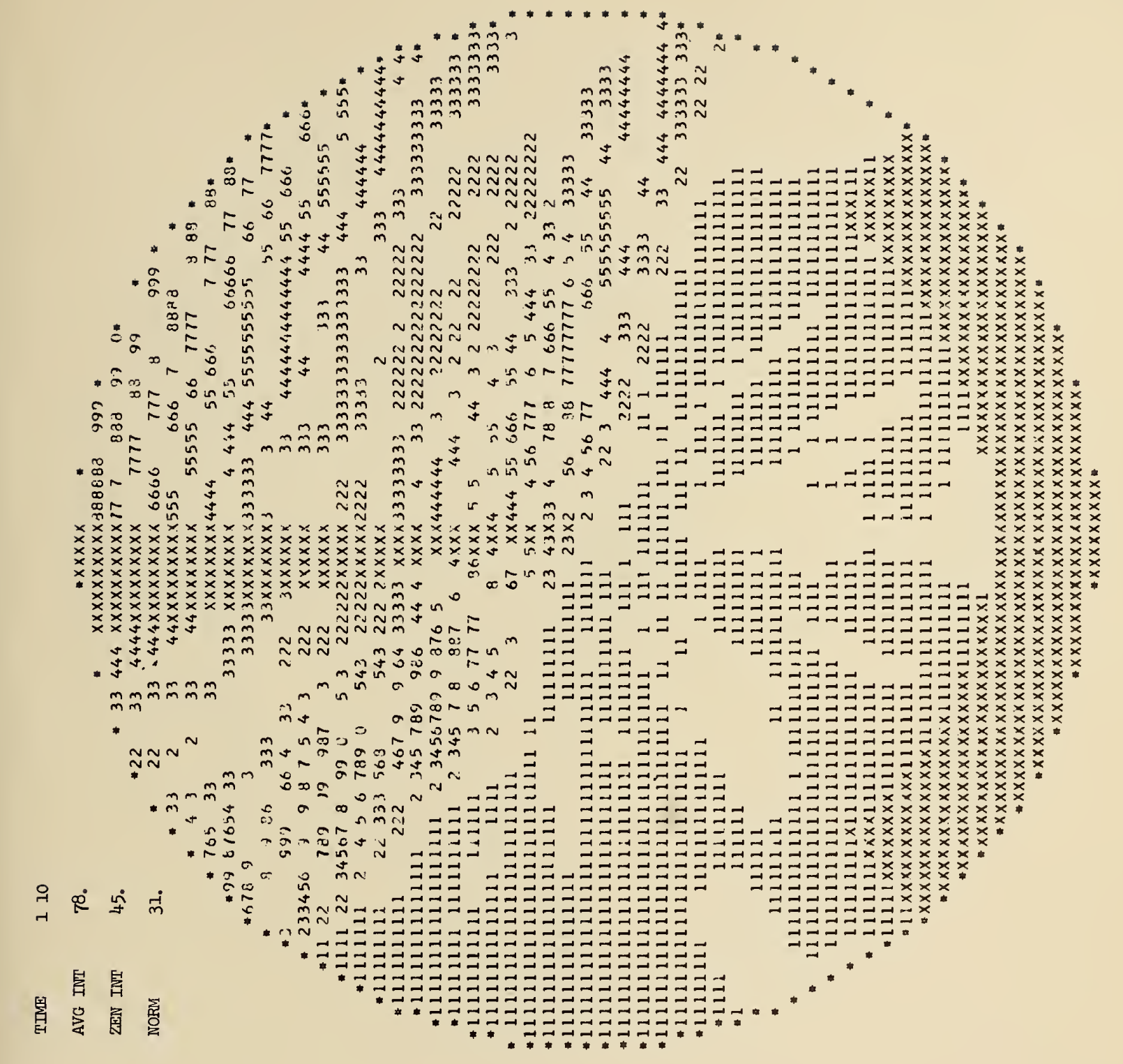





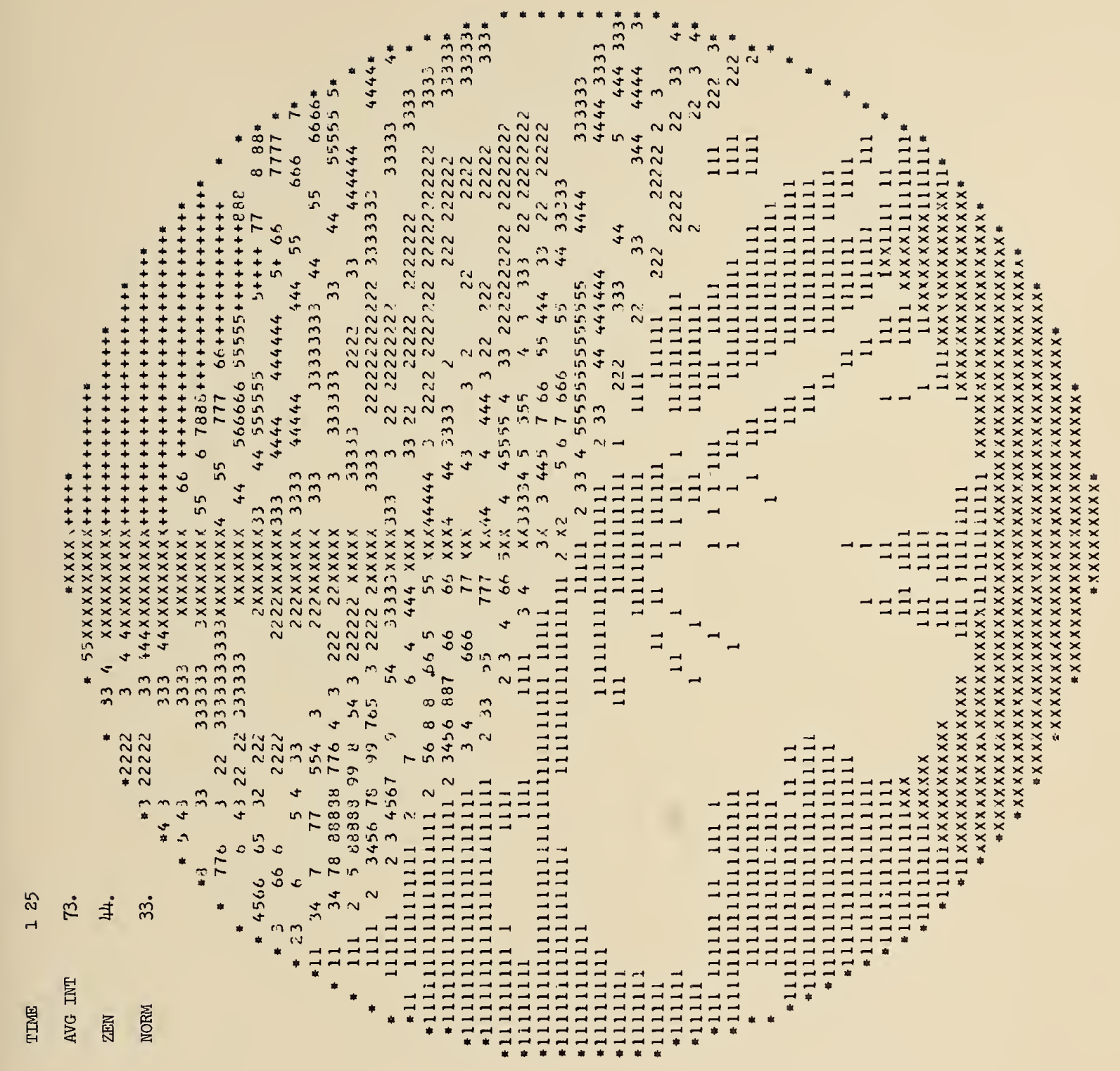





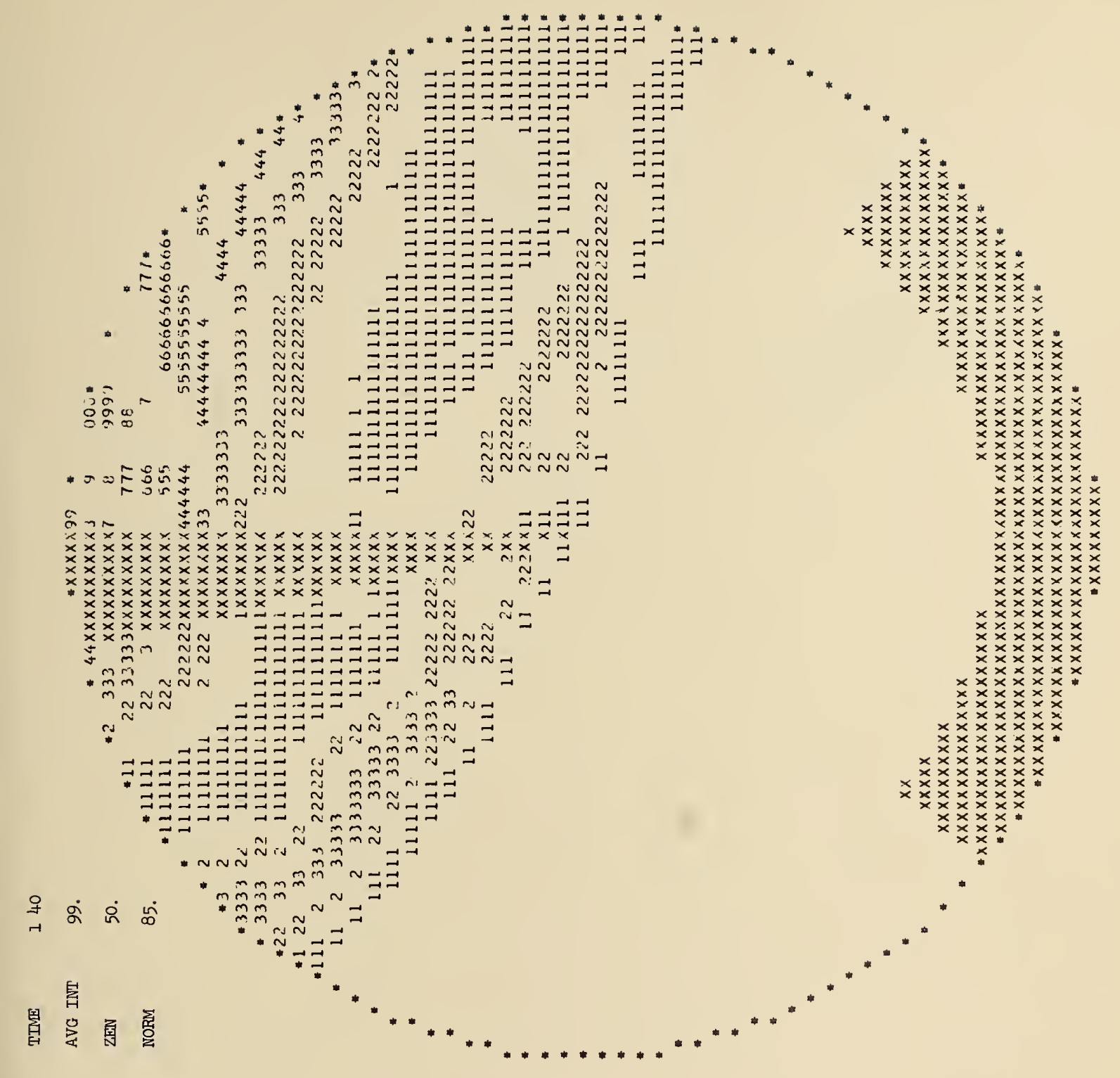





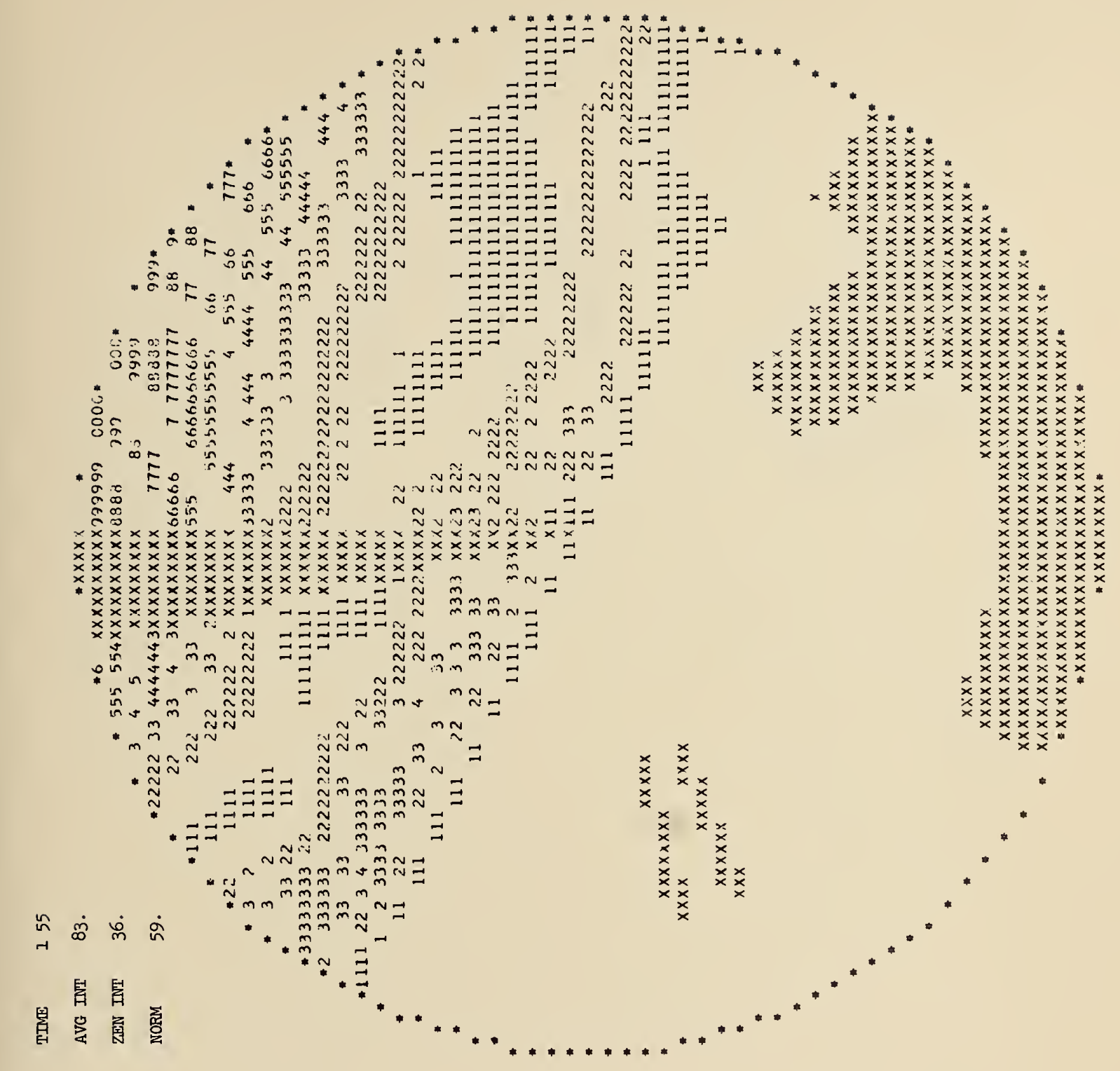





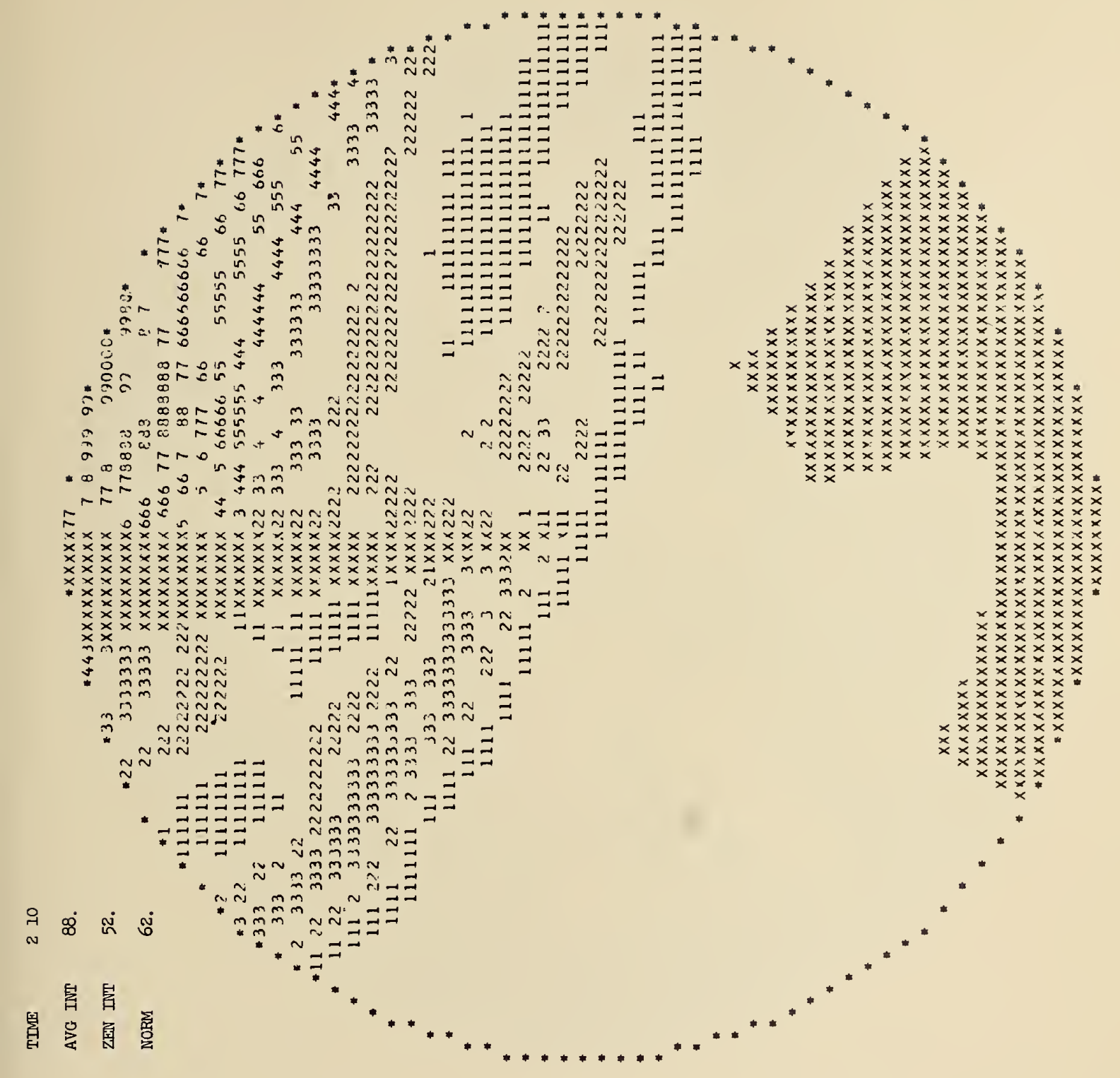





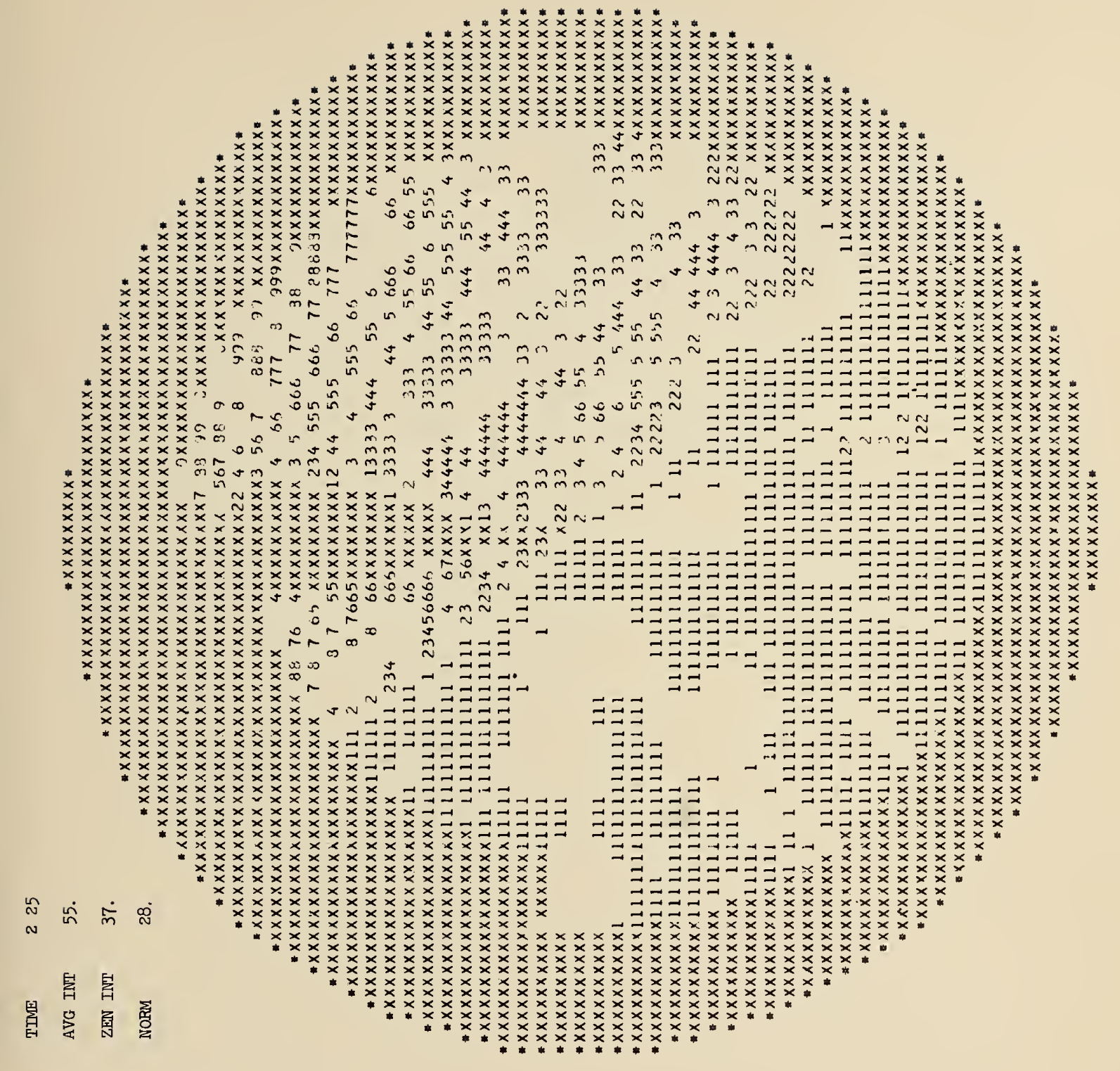





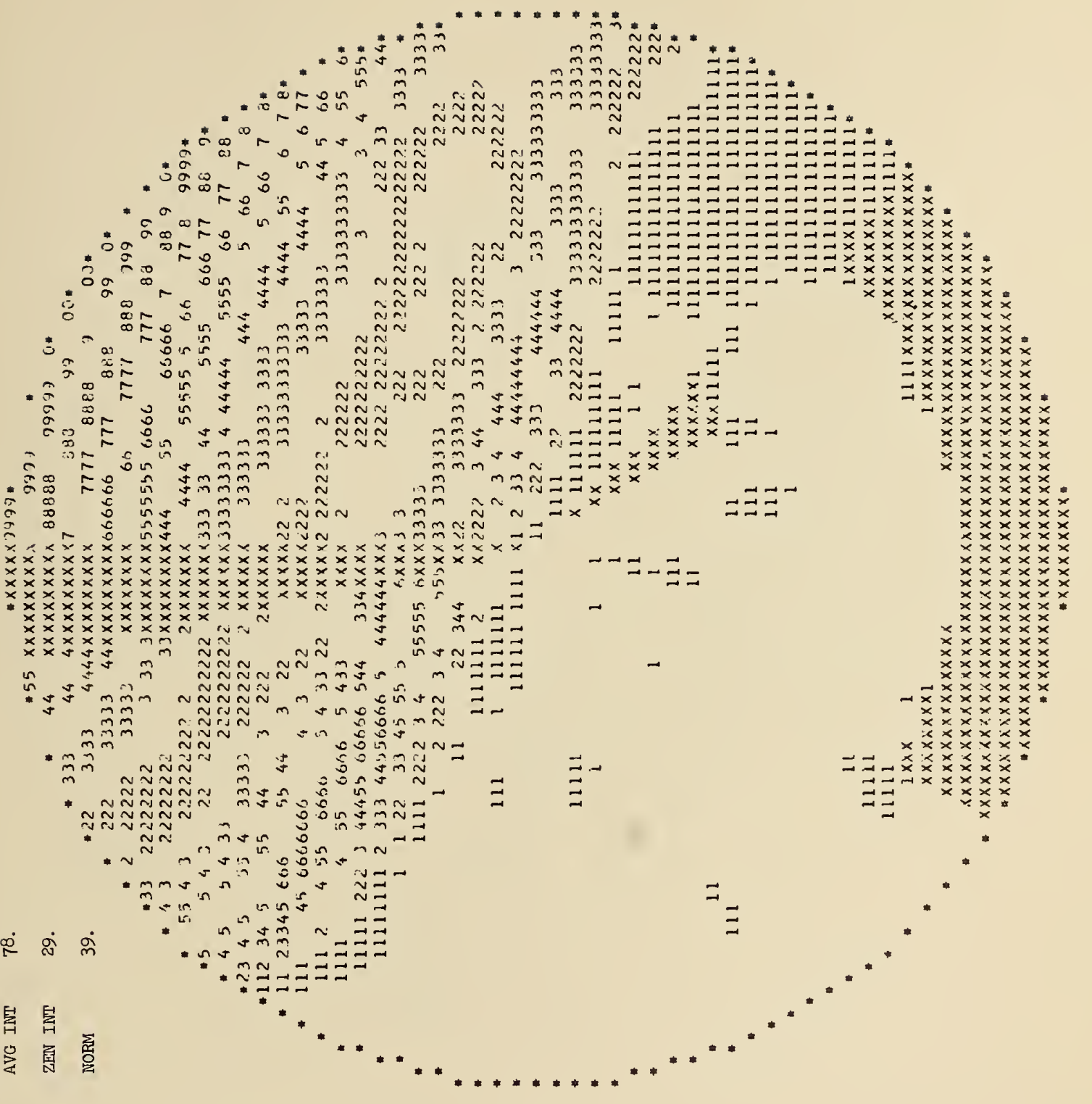






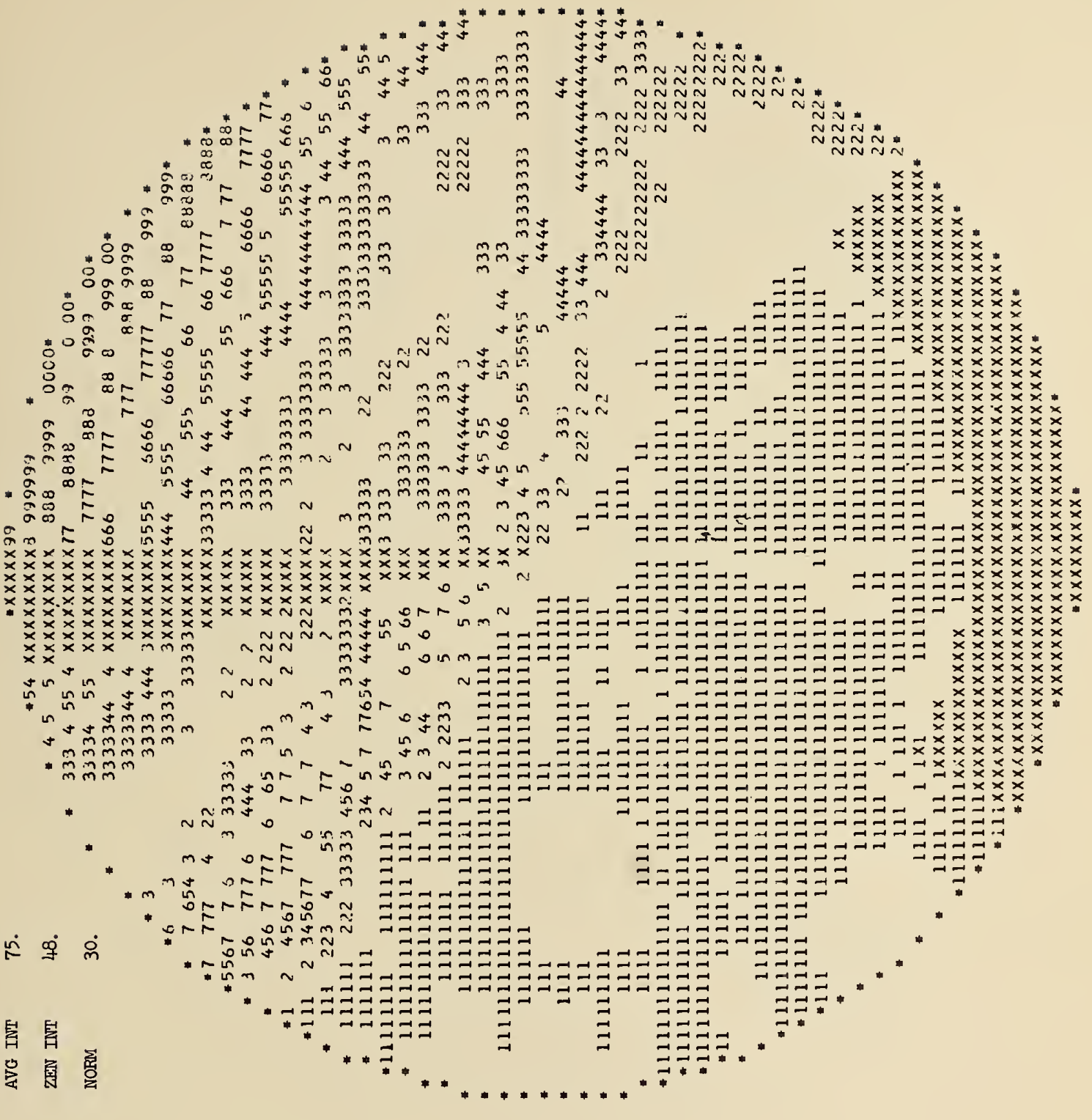






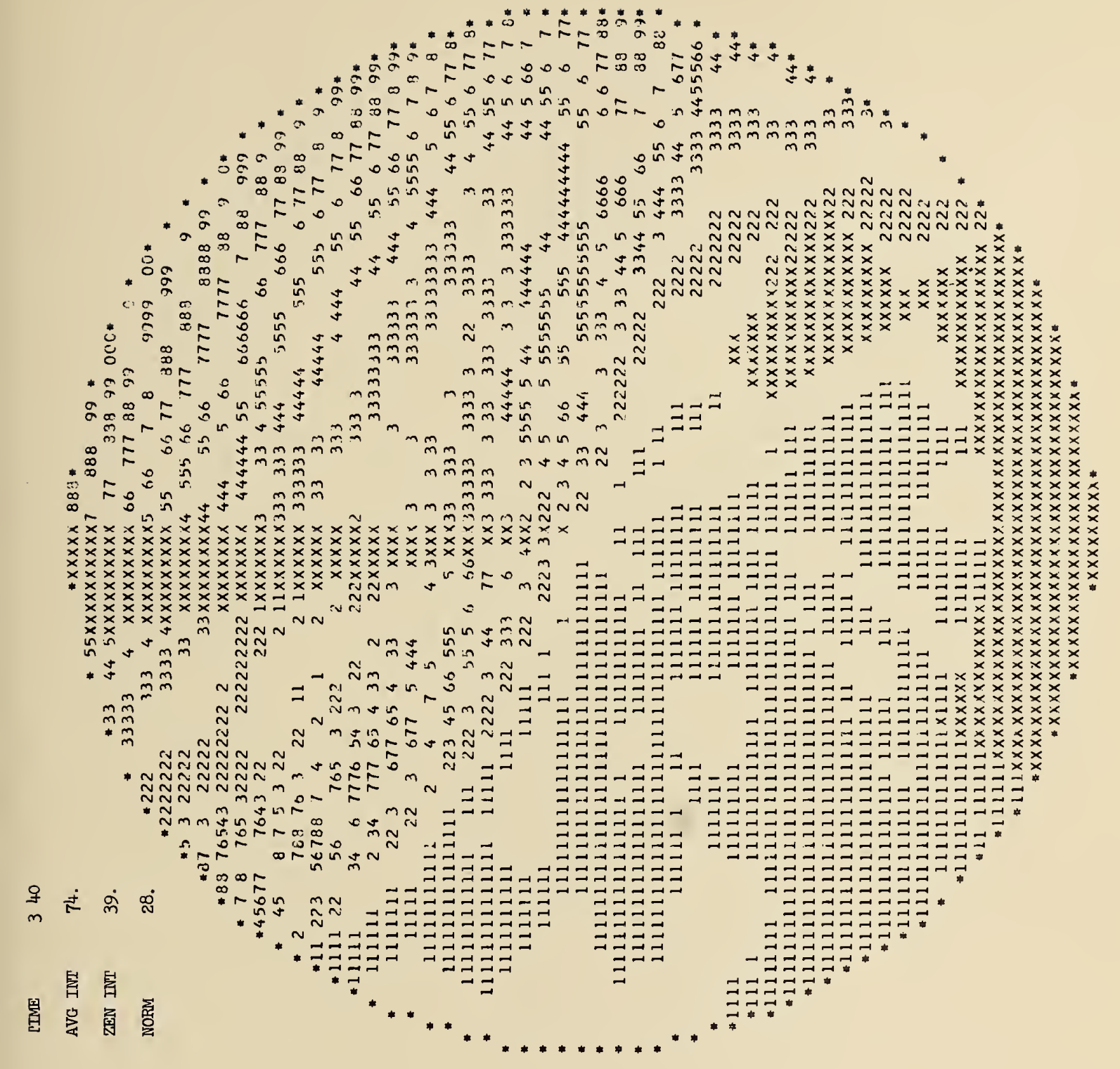






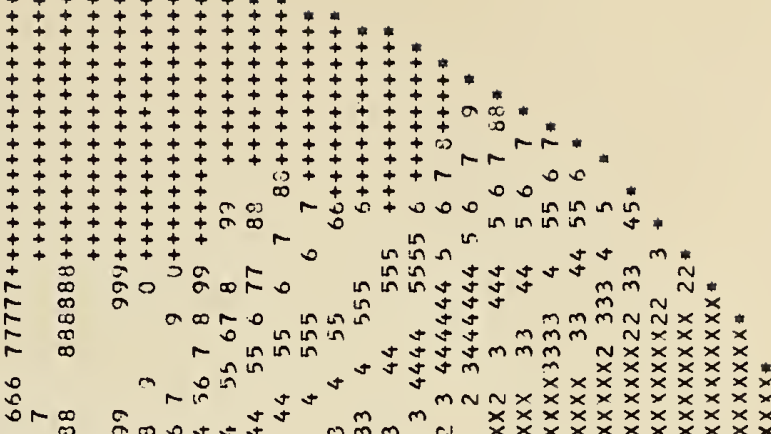

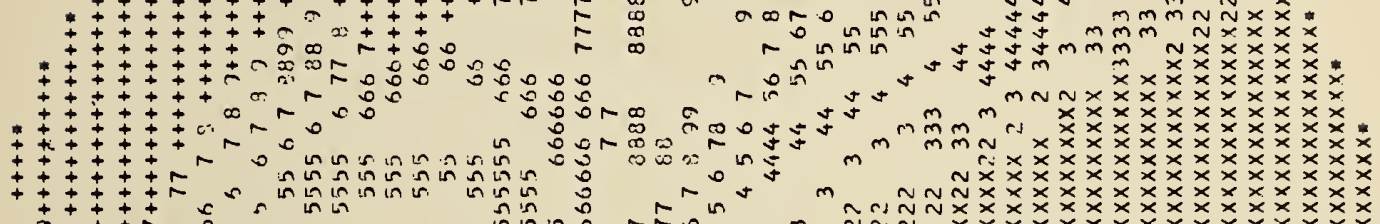

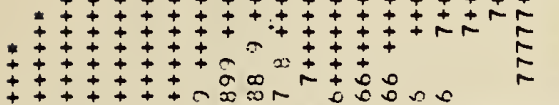

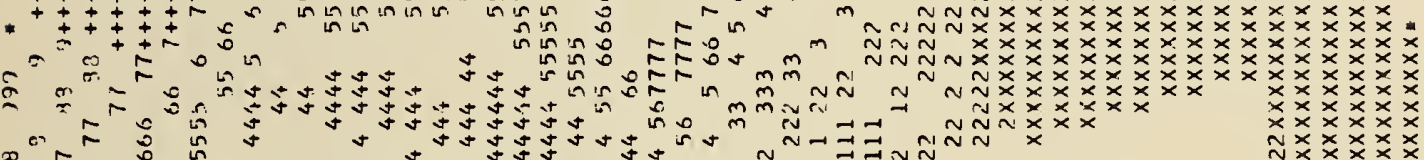
- m

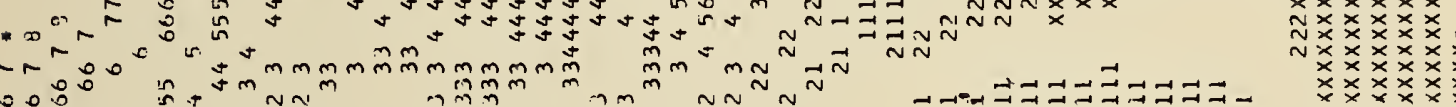

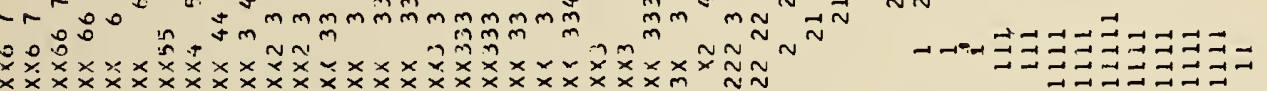

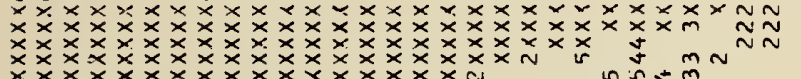

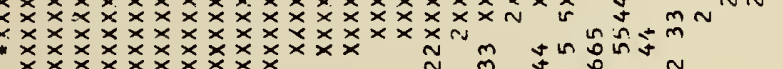

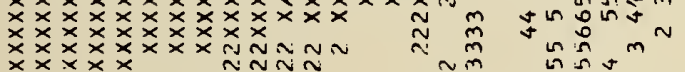

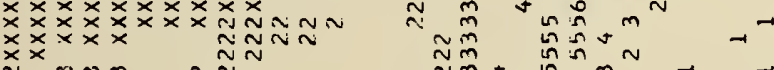


(1)

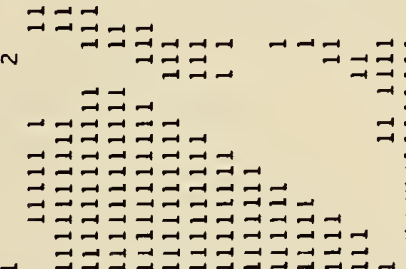

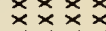
x $\times \times \times \times x$ $x \times \times \times x \times$

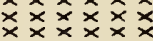

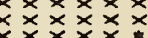

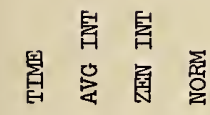
.

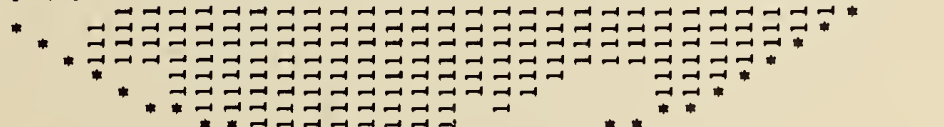

$x \times x \times x \times x$
$x \times x$
$x \times x$ axx $x \times x \times x$ $x \times x \times x \times x$

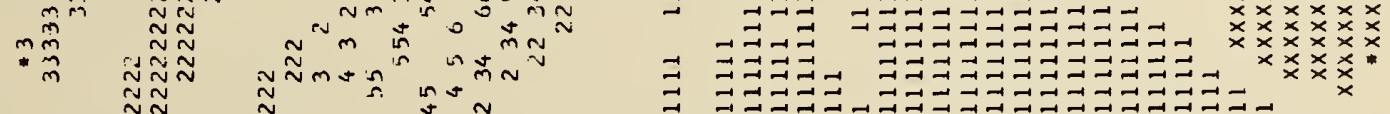

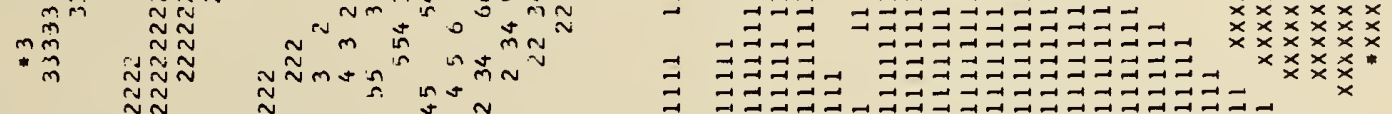

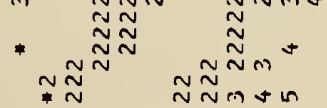

$$
\text { * }
$$

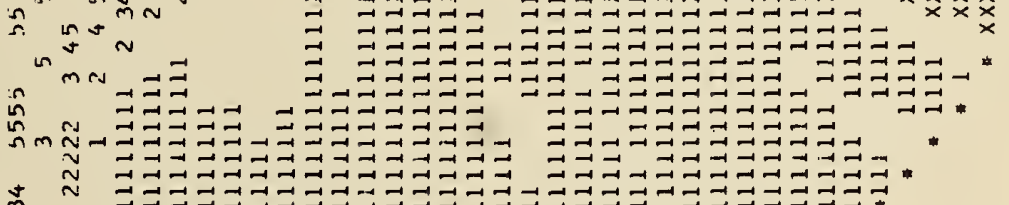





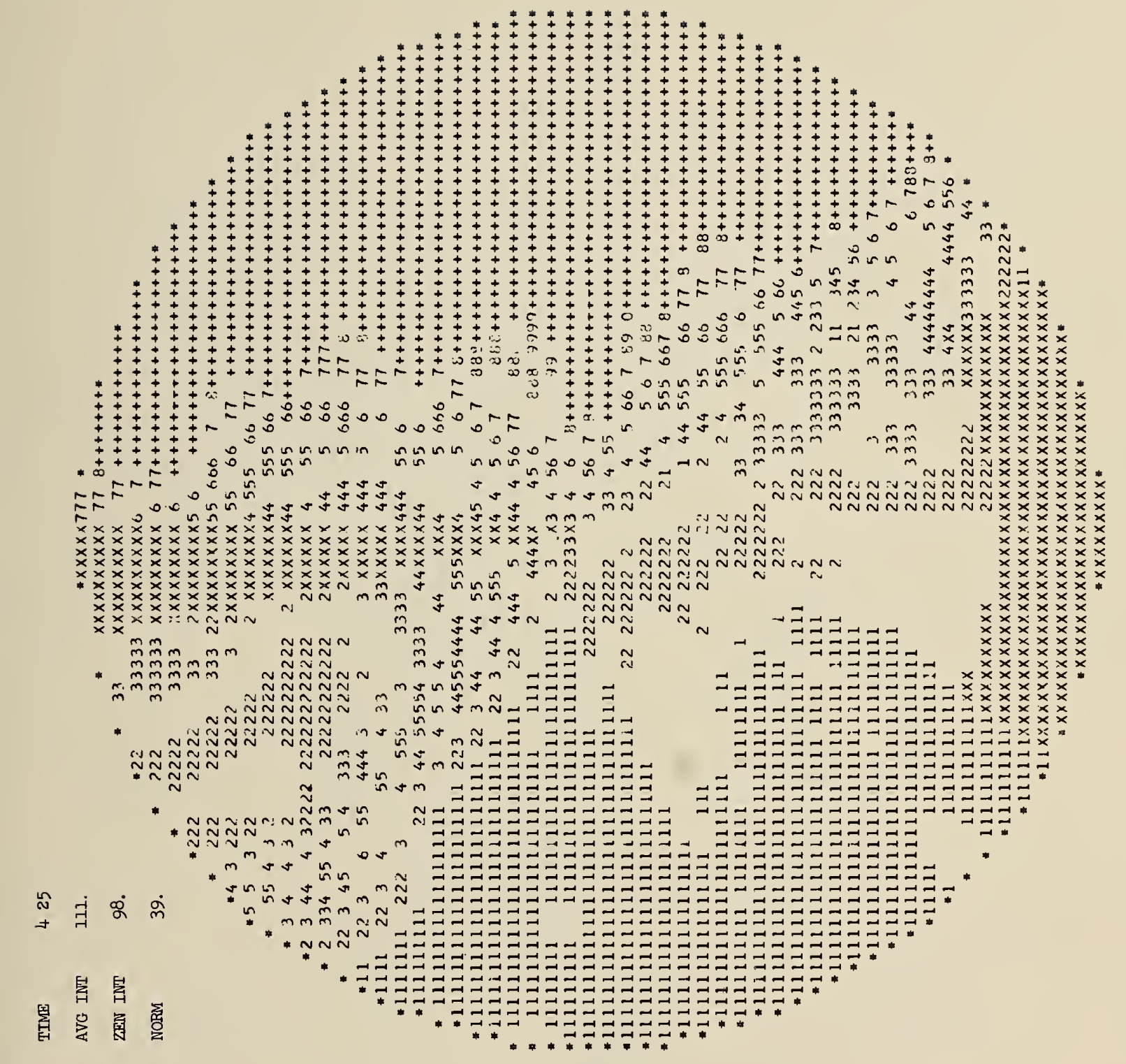



